\title{
Review on Pervaporation: Theory, Membrane Performance, and Application to Intensification of Esterification Reaction
}

\author{
Ghoshna Jyoti, Amit Keshav, and J. Anandkumar \\ Department of Chemical Engineering, National Institute of Technology, Raipur 492010, India \\ Correspondence should be addressed to Amit Keshav; dr.amitkeshav@gmail.com
}

Received 11 September 2015; Revised 17 November 2015; Accepted 26 November 2015

Academic Editor: Georgiy B. Shul'pin

Copyright (C) 2015 Ghoshna Jyoti et al. This is an open access article distributed under the Creative Commons Attribution License, which permits unrestricted use, distribution, and reproduction in any medium, provided the original work is properly cited.

\begin{abstract}
The esterification reaction is reversible and has low yield. In order to increase the yield of reaction, it is required to simultaneously remove the product of reaction. For this membranes are the viable approach. Pervaporation membranes have success in removal of components in dilute forms. Membrane performance is represented in terms of flux, sorption coefficient, separation factor, and permeance. These factors are related to the thickness of membrane, temperature, and feed concentration. Higher flux is observed at lower membrane thickness and higher feed concentration of water and lower selectivity is observed at higher temperatures due to increased free volume, lower viscosity, and higher feed side pressure. Different factors affect the pervaporation aided esterification reactor setup such as effect of initial molar ratios of the reactants, effect of catalyst concentration, effect of membrane area, and effect of temperature. Large membrane size could provide higher surface for the transfer of acid, though the challenges of membrane rupture do surround the studies. In the present review work, we tried to collaborate the works in totality of the pervaporation design starting from the membrane behavior to the process behavior. Different prospective fields are also explored which need investigation.
\end{abstract}

\section{Introduction to Pervaporation}

Separation of liquid mixtures by partial vaporization through a membrane (nonporous or porous) is the separation principle in pervaporation. This results in collection of permeating component in vapor form, which may be either removed by flowing an inert medium or applying low pressure on the permeant side. The driving force for pervaporation process is the difference in chemical potential, corresponding to the concentration gradient between phases on the opposite sides of the interfacial barrier. Sorption diffusion model is used to describe the transport on the basis of difference in the molecular size instead of volatility as in the case of distillation. Thus, it could be effectively utilized as economical substitute azeotropic separations. In addition to this the no use of third component and requirement of low energy consumption (due to energy integration) are the add-on benefits $[1,2]$. In the last two decades, pervaporation is finding wide range of areas for its application such as liquid hydrocarbons separations (petrochemical application, alcohol/ether separations) [3-5], removal of volatile organic compounds (VOCs) from water $[6,7]$, removal of water from glycerin [8], and dehydration to intensify esterification reaction $[9,10]$.

Pervaporation can be integrated with either distillation or a chemical production step to provide intensification and energy integration. Pervaporation-distillation hybrid system leads to a clean technology and offer potential savings in energy because of reduced thermal and pressure requirements. When integrated with reactions such as esterification process, it offers the opportunity to shift the chemical equilibrium by removing the product of the reaction. Reactorpervaporation hybrid method overcomes the inhibition of the chemical equilibrium of the process and therefore leads to an increased productivity. This process also allows one to use heat of the chemical reaction to increase the efficiency of the pervaporation process and leads consequently to potential savings in energy costs.

Membranes are successfully used in separation industries as selective barriers to prevent unwanted solutes from permeating through. Thus the impurity is separated from the target. 


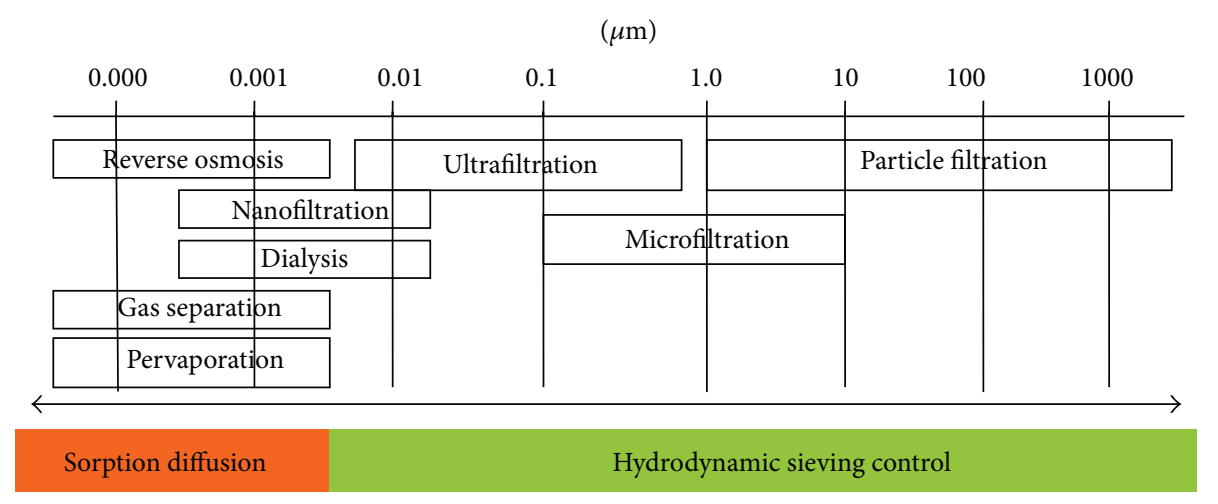

FIGURE 1: The choice of membrane with respect to the size of particles encountered.

Separation is based on pore sizes and hence the membranes got their characteristic names as microfiltration, ultrafiltration, and nanofiltration membranes (Figure 1). Membranes are either porous or nonporous and in the separation based on sizes, usually porous membranes are used. Pervaporation is the distinction class among above membranes as the separation criteria are different. Pervaporation membranes are nonporous and have been widely employed for separating liquid mixtures. The separation feature is based on affinity with membrane materials and hence the molecule having higher affinity is adsorbed and diffuses through the membrane while the membrane retains molecules having low affinity.

\section{Membrane Materials for Pervaporation}

For pervaporation, the hydrophilic membranes were the first one to achieve the industrial applications and were used for the organic solvent dehydration. The main industrial applications in pervaporation even today are almost the same as before, which is the dehydration of organic liquids. By modifying the active layer of these membranes with different chemical compositions and structures, these membranes are enabled to extract water with broad ranges of flux and selectivity $[11,12]$. Commercially available hydrophilic membranes are made of polymeric membrane materials such as polyvinyl alcohol (PVA), polyimides, polymaleimides, Nafion, and polyacrylonitrile (PAN).

Presently there have been a number of investigators concerning R\&D of the hydrophilic membrane, which can be cataloged into organic, inorganic, and organic-inorganic hybrid membranes. Inorganic membranes such as zeolite and silica are generally used $[13,14]$. Inorganic membranes are very suited for high temperature applications (harsh environments) and generally these membranes are prepared by sol-gel method, which was appropriate to elaborate thin and porous layers with controllable porosity on a wide range of chemically resistant macroporous substrates [15]. While these inorganic membranes showed high dehydration efficiency, their industrialization process may be slow-paced due to the complicated large-scale preparation and high manufacturing cost. In addition to this, several kinds of commercial organic membranes including PERVAP 2201 [16, 17], PERVAP 1005 (GFT) [18], and GFT-1005 [19] have been introduced to the pervaporation-esterification coupling process. Few studies on cross-linked poly(vinyl alcohol) membranes have also been investigated, such as PVA with catalyst $\mathrm{Zr}\left(\mathrm{SO}_{4}\right)_{2} \cdot 4 \mathrm{H}_{2} \mathrm{O}$ and Amberlyst [20, 21], cast on polyethersulfone [22, 23] and on poly(acrylonitrile) [24]. However, the inherent instabilities of these organic membranes severely limit their applications.

Organic-inorganic hybrid materials have been proposed to be the best choice for having both the functionality of the organic moiety and the stability of inorganic moiety. Budd et al. [25] employed zeolite/polyelectrolyte (chitosan/poly(4styrene sulfonate)) multilayer pervaporation membranes to enhance the yield of ethyl lactate. Adoor et al. [26] prepared aluminum-rich zeolite beta incorporated sodium alginate pervaporation membranes. Organic-inorganic hybrid membranes showed improved performance of pervaporative dehydration of solution, with better flux and retention.

Hydrophobic membranes used as pervaporation membranes are used to separate volatile organic compounds from the body of water. Hydrophobic membrane systems utilize molecules made from proprietary polymeric hollow fiber membranes. The membrane only permits the volatile organic compound and rejects water molecule due to its hydrophobic nature. Hence, pervaporation integrated with membrane separation technology serves as an interesting subject for the separation of organic compounds such as pollutants and high-value products like aroma compounds. Here the membranes employed are polymeric in nature [27-29]. Rarely, ceramic membranes [30-34] can also be used. However, when it comes to recovering volatile polar organics from their very dilute solutions in water [35], the selectivity exhibited by polymeric membranes, as well as ceramic membranes, is not high [36-38].

One of the most applied polymeric materials for organic separation is polydimethylsiloxane (PDMS). PDMS exhibits high selectivity and permeability towards organic substances because of the flexible structure and therefore is preferred for the removal of organic compounds from water [39]. Organic liquid membranes of oleyl alcohol (OA) were found to demonstrate high selectivity for recovering species like n-butanol and acetone [40] from simulated fermentation 


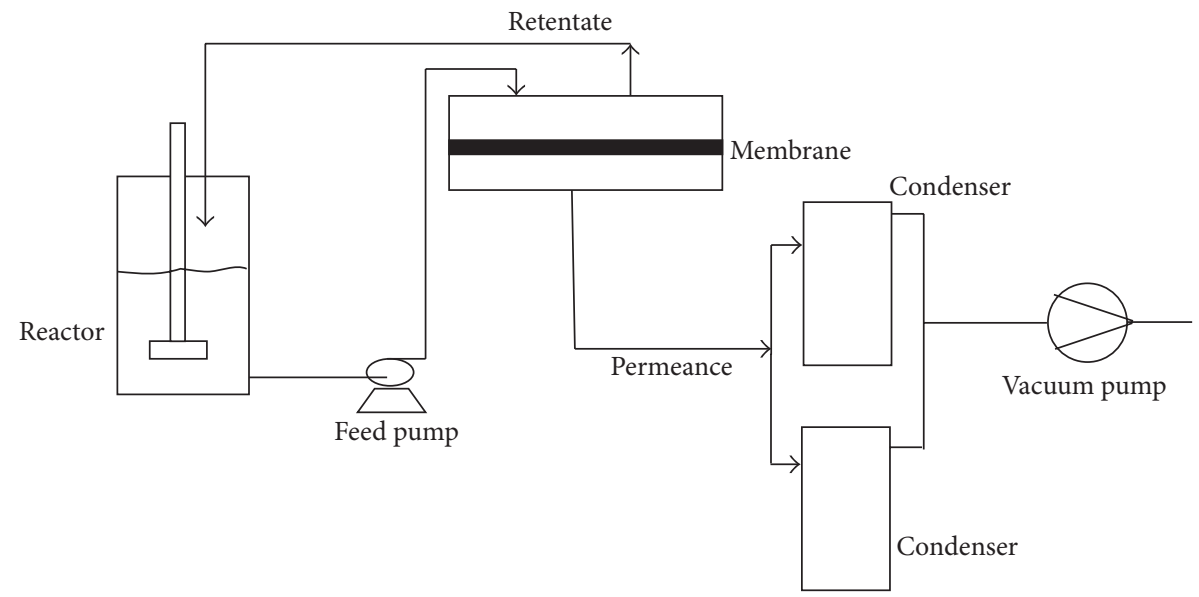

FIGURE 2: Schematic diagram of pervaporation-chemical reactor integrated system.

broths. Employing tri-n-octylamine (TOA) as a supported liquid membrane (SLM), Thongsukmak and Sirkar [41] prepared liquid membrane of trioctylamine (TOA) in the coated hollow fibers and demonstrated high selectivity of as much as 275,220 , and 80 for n-butanol, acetone, and ethanol from a very dilute solution representative of an acetone$\mathrm{n}$ butanol-ethanol (ABE) fermentation broth $(1.5 \mathrm{wt} \% \mathrm{n}$ butanol, 0.8 wt $\%$ acetone, and 0.5 wt $\%$ ethanol).

In hybrid configuration as the pervaporation membrane reactor, esterification is a typical example in which pervaporation is used for removal of the product or the byproduct of a reaction (Figure 2). Esterification reactions are typically reversible and equilibrium limited processes with ester and water as products. Pervaporation-membrane reactors (PVMR) have a selective membrane for removal of water from the esterification reaction mixtures and hence achieve a higher yield of ester. In pervaporation-esterification coupling systems, several types of commercial membranes are used including GFT-1005 [19], polydimethylsiloxane [42], PERVAP 2201 [16, 43], and PERVAP 1005 [44, 45]. Table 1 shows the various membranes employed for the pervaporationesterification integrated system for the synthesis of several esters such as methyl acetate, ethyl acetate, isobutyl acetate, ethyl acrylate, and ethyl lactate.

Zhang et al. [46] employed three types of composite membrane, namely, glutaral cross-linked chitosan (GCCS)/ carbomer (CP)/polyacrylonitrile (PAN), glutaral crosslinked gelatin (GCGE)/PAN, and glutaral cross-linked hyaluronic acid (GCHA)/hydrolysis modification- (HM-) PAN, to study esterification of lactic acid and ethanol. In GCCS/ $\mathrm{CP} / \mathrm{PAN}$ composite membrane, the content of the $\mathrm{CP}$ is $0.5 \mathrm{wt} \%$ and the molar ratio of the CS repeating unit to GA is 60. For GCGE/PAN composite membrane, the content of the $\mathrm{GE}$ is $2 \mathrm{wt} \%$ and the mass ratio of the GA to GE is 2.5 and in the case of GCHA/HM-PAN membrane, the content of the $\mathrm{HA}$ is $0.8 \mathrm{wt} \%$ and the cross-linking degree is 0.3 . Korkmaz et al. [47] employed ester-permeable polydimethylsiloxane (PDMS) and the water-permeable poly(vinyl alcohol) membranes to study the esterification of acetic acid with isobutanol. They prepared the membranes in laboratories which are composed of the respective polymer and a crosslinking agent. Zhang et al. [48] employed a catalytically active pervaporation membrane to enhance the conversion of esterification reaction of acetic acid and n-butanol. The membrane used consists of three layers: a support layer (commercial PES porous membrane), a separation layer (PVA pervaporation membrane), and a porous catalytic layer with the loading of catalysts.

Currently it is great deal of interest in pervaporation assisted production of enzymatic esters by lipase-catalysed chemical esterification reaction, because higher selectivity can be achieved by the biotechnological way, as milder reaction conditions should be applied; thus, energy demand, cost of production, and byproduct formation can be simultaneously reduced and the conversion or yield of biodiesels can be enhanced [49, 50]. Krishna et al. [51] studied the esterification of isoamyl alcohol with acetic acid in n-heptane solvent using immobilized lipase from Mucor miehei. They presented relationship between esterification variables (substrate and enzyme concentrations and incubation period) and ester yield to determine optimum conditions for the synthesis of isoamyl acetate catalyzed by Lipozyme IM-20 (immobilized lipase from Mucor miehei). They observed that conversion over $95 \%$ achieved at even very low enzyme concentrations. Ziobrowski et al. [50] presented the enzymatic production of glycerol monostearate in different high polar organic solvents to remove water produced during the esterification process using pervaporation. Shieh et al. [49] investigated a commercial immobilized lipase from Rhizomucor miehei (Lipozyme IM-77) to catalyze the transesterification of soybean oil and methanol. They developed relationships between the variables (reaction time, temperature, enzyme amount, substrate molar ratio, and added water content) and the response (percent weight conversion) and obtained the optimum conditions for biodiesel synthesis using central composite rotatable design (CCRD) and RSM analysis. Koszorz et al. [45] studied the kinetics of enzymatic esterification of oleic acid and i-amyl-alcohol (main compound of fusel oil). In the experiments an immobilized lipase enzyme, Novozym 435 (Novo Nordisk, Denmark), which was taken as a catalyst and 
TABLE 1: Pervaporation membranes employed for various esterification reactions.

\begin{tabular}{|c|c|c|c|}
\hline Membranes & Nature of membrane & Esterification reactions studied & Reference \\
\hline $\begin{array}{l}\text { Chitosan-tetraethoxysilane hybrid } \\
\text { membrane }\end{array}$ & $\begin{array}{l}\text { Hydrophilic organic-inorganic hybrid } \\
\text { membrane }\end{array}$ & Lactic acid + ethanol & [73] \\
\hline \multirow{2}{*}{ Nafion membrane } & \multirow{2}{*}{ Hydrophilic catalytically active membrane } & Acetic acid + methanol & {$[94]$} \\
\hline & & Acetic acid + butanol & [94] \\
\hline \multirow{2}{*}{ GFT-1005 and T1-b membrane } & \multirow{2}{*}{ Hydrophilic organic membrane } & Lactic acid + ethanol & {$[19]$} \\
\hline & & Succinic acid + ethanol & {$[19]$} \\
\hline \multirow{2}{*}{ Polydimethylsiloxane membrane [PDMS] } & \multirow{2}{*}{ Hydrophobic cross-linked membrane } & Acetic acid + isobutanol & {$[95]$} \\
\hline & & Acetic acid + ethanol & [42] \\
\hline \multicolumn{4}{|l|}{ PERVAP } \\
\hline [2201] & \multirow{10}{*}{ Hydrophilic polymeric membrane } & Lactic acid + ethanol & {$[16]$} \\
\hline [2201] & & Lactic acid + ethanol & [9] \\
\hline [2201] & & Lactic acid + ethanol & {$[96]$} \\
\hline$[2216]$ & & Lactic acid + ethanol & {$[96]$} \\
\hline$[1000]$ & & Acetic acid + ethanol & {$[97]$} \\
\hline$[2201]$ & & Acetic acid + isopropanol & [43] \\
\hline$[2201]$ & & Propionic acid + isopropanol & {$[98]$} \\
\hline [1005] & & Oleic acid + i-amyl alcohol & {$[45]$} \\
\hline$[1005]$ & & Acetic acid + ethanol & {$[18]$} \\
\hline$[1005]$ & & Acetic acid + benzyl alcohol & [44] \\
\hline $\begin{array}{l}\text { Polyetherimide- } \gamma \text { alumina composite } \\
\text { membrane }\end{array}$ & $\begin{array}{l}\text { Hydrophilic composite polymeric-inorganic } \\
\text { membrane }\end{array}$ & Acetic acid + ethanol & {$[99]$} \\
\hline Silica membrane [Pervatech BV] & Hydrophilic inorganic membrane & Lactic acid + ethanol & {$[13]$} \\
\hline Polyetherimide composite membrane & Polymeric/ceramic membrane & Acetic acid + ethanol & {$[100]$} \\
\hline PVA membrane & $\begin{array}{l}\text { Hydrophilic polymeric/ceramic composite } \\
\text { membrane }\end{array}$ & Acetic acid + n-butanol & $\begin{array}{l}{[89]} \\
{[87]} \\
{[101]} \\
\end{array}$ \\
\hline $\begin{array}{l}\text { PVA membrane cross-linked with catalyst } \\
\mathrm{Zr}\left[\mathrm{SO}_{4}\right]_{2} \cdot 4 \mathrm{H}_{2} \mathrm{O}\end{array}$ & Polymeric composite catalytic membrane & Acetic acid + butanol & {$[20]$} \\
\hline PVA membrane [Amberlyst coated] & Polymeric/ceramic composite membrane & Acetic acid + butanol & {$[21]$} \\
\hline \multirow{2}{*}{$\begin{array}{l}\text { PVA membrane [cast on } \\
\text { polyethersulfone] }\end{array}$} & \multirow{2}{*}{$\begin{array}{l}\text { Hydrophilic polymeric composite } \\
\text { membrane }\end{array}$} & Oleic acid + methanol & {$[22]$} \\
\hline & & $\begin{array}{l}\text { 2,2,2, Trifluoroethanol + } \\
\text { methacrylic acid }\end{array}$ & {$[23]$} \\
\hline $\begin{array}{l}\text { Zeolite membrane [aluminum rich zeolite } \\
\text { beta incorporated sodium alginate] }\end{array}$ & Hydrophilic mixed matrix membrane & Acetic acid + ethanol & {$[26]$} \\
\hline \multirow{2}{*}{ Zeolite T membrane } & \multirow{2}{*}{ Hydrophilic membrane } & Acetic acid + n-butanol & {$[102]$} \\
\hline & & Acetic acid + ethanol & {$[103]$} \\
\hline \multirow{2}{*}{ Zeolite NaA membrane } & \multirow{2}{*}{ Hydrophilic membrane } & Lactic acid + ethanol & {$[14]$} \\
\hline & & Propionic acid + isopropanol & {$[98]$} \\
\hline Poly[ether block amide] membrane & Organophilic membrane & Acetic acid + n-butanol & [104] \\
\hline $\begin{array}{l}\text { Poly[2,6-dimethyl-1,4-phenylene oxide] } \\
\text { [PPO] and thin layer fluoroplastic }\end{array}$ & Hydrophobic composite membrane & Acetic acid + methanol & {$[105]$} \\
\hline \multirow{2}{*}{$\begin{array}{l}\text { Tubular hydroxy sodalite [SOD] } \\
\text { membrane }\end{array}$} & \multirow{2}{*}{ Hydrophilic membrane } & Acetic acid + ethanol & {$[106]$} \\
\hline & & Acetic acid + butanol & {$[106]$} \\
\hline HZSM-5 membrane & Hydrophilic catalytic active membrane & Acetic acid + ethanol & {$[107]$} \\
\hline $\begin{array}{l}\text { Poly[2,6-dimethyl-1,4-phenylene oxide] } \\
\text { [PPO] and fullerene } \mathrm{C}_{60}\end{array}$ & Hydrophobic composite membrane & Acetic acid + ethanol & {$[108]$} \\
\hline
\end{tabular}




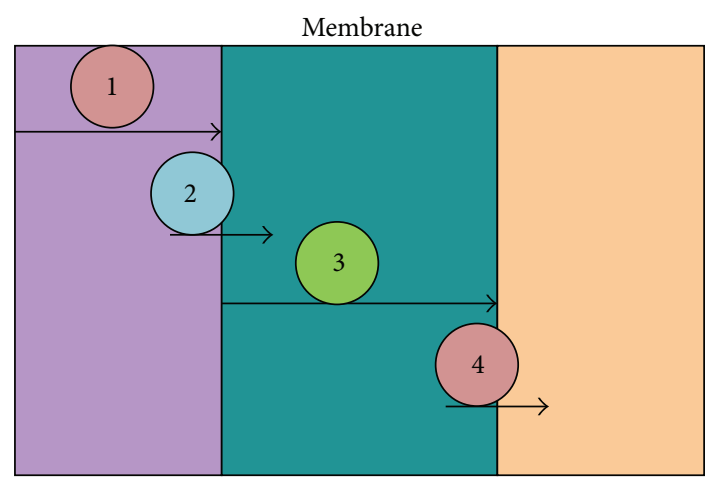

FIGURE 3: Steps involved in transport of component through a pervaporation membrane.

proved to be very sensitive for the presence of water and alcohol in the reaction mixture.

\section{Theory of Pervaporation}

The transport of component across the membrane in pervaporation is described by solution desorption model that results from these processes in series: (i) diffusion of the component through the liquid boundary layer to the membrane surface, (ii) sorption/diffusion into the membrane, (iii) transport through the membrane, and (iv) diffusion through the vapor phase boundary layer into the bulk of the permeance (Figure 3). In modeling the transport model for pervaporation, it is assumed that the resistance offered by the boundary layer at the vapor phase is negligible and that the concentration of the solute is zero at the permeant side, since the permeant side is maintained at a low vacuum. At increased permeant pressure, however, the resistance to transport on the vapor side will increase and become significant.

Transport through the boundary layer on the liquid feed side of the membrane is given by

$$
J_{a}^{\mathrm{bl}}=k_{l} \rho\left(x_{f}-x_{i, l}\right)
$$

where $k_{l}$ is the boundary layer mass transfer coefficient on the liquid side and $x_{i, l}$ and $x_{f}$ are the organic concentration at the liquid-membrane interface and feed side, respectively.

Membrane transport is given by

$$
J_{o}^{m}=k_{i} \rho\left(x_{m, l}-x_{m, g}\right)
$$

where $k_{i}$ is membrane mass transfer coefficient, $t$ is membrane thickness, and $x_{m, l}$ and $x_{m, g}$ are the organic concentration at the membrane in liquid phase and vapor phase, respectively.

Overall organic flux is described by

$$
J_{i}=K_{\mathrm{ov}} \rho\left(x_{f}-x_{p}\right)
$$

where the subscripts $f$ and $p$ refer to feed and permeance. It can also be expressed in terms of partial vapor pressure, concentration of $i$, or fugacity as $[52,53]$

$$
\begin{aligned}
& J_{i}=Q_{\mathrm{ov}, i} A\left(p_{l, i}-p_{g, i}\right)=K_{\mathrm{ov}, l} A\left(C_{l, i}-C_{g, i}^{*}\right), \\
& J_{i}=K_{\mathrm{ov}, i}\left(f_{i}^{\mathrm{feed}}-f_{i}^{\text {permeate }}\right),
\end{aligned}
$$

where $J_{i}$ is the flux of $i$ across the membrane, $Q_{\mathrm{ov}, i}$ is the overall mass transfer coefficient of $i$ in terms of vapor pressure, $A$ is the membrane area, $p_{l, i}$ and $p_{g, i}$ are partial vapor pressures of $i$ in the liquid side and in the permeant (or gas) side, respectively, $K_{\mathrm{ov}, l}$ is the overall mass transfer coefficient of $i$ in terms of liquid concentration, $C_{l, i}$ is the concentration of $i$ in the liquid, and $C_{g, i}^{*}$ is the concentration of $i$ in the liquid which would be in equilibrium with the gas. In pervaporation, the partial vapor pressure is preferred as a measure of the driving force since the effects of temperature on the driving force and on the mass transfer coefficients are separated more clearly.

The partial vapor pressure of $i$ in the liquid side is related to the concentration in the liquid side $\left(C_{l, i}\right)$ by the expression given by [54]

$$
p_{l, i}=\frac{C_{l, i} \gamma_{i} p_{i}^{0}}{\rho_{l}},
$$

where $\gamma_{i}$ is the activity coefficient of $i$ in the liquid side, $p_{i}^{0}$ is the saturation vapor pressure of pure $i$ at the liquid temperature, and $\rho_{l}$ is the molar density of the liquid. The partial vapor pressure of $i$ in the gas side is related to the concentration in the gas side $\left(C_{g, i}\right)$ by the expression

$$
p_{g, i}=\frac{C_{g, i} p_{T}}{\rho_{g}},
$$

where $p_{T}$ is the total pressure in the gas side and $\rho_{g}$ is the molar density of the gas. $K_{\mathrm{ov}, i}$ in (5) is the apparent mass transfer coefficient and $f_{i}$ is fugacity. The fugacity of component in the feed and in permeance can be expressed as follows:

$$
\begin{aligned}
f_{i}^{\text {feed }} & =\gamma_{i} x_{i}^{\mathrm{feed}} p_{i}^{o}\left(T^{\mathrm{feed}}\right), \\
f_{i}^{\text {permeate }} & =\gamma_{i} P_{p},
\end{aligned}
$$

where $p_{i}^{o}$ is the vapor pressure of compound $i, \gamma_{i}$ is activity coefficient, $T^{\text {feed }}$ is the feed temperature, and $p_{T}$ is total pressure.

The membrane mass transfer coefficient $\left(k_{i}\right)$ includes sorption to, diffusion through, and desorption from the membrane. It is equivalent to the relation between the permeability coefficient $\left(P_{i}\right)$ and the thickness of the active layer of the membrane $(l)$ as shown in

$$
\begin{aligned}
& k_{i}=\frac{P_{i}}{l}, \\
& P_{i}=S_{i} D_{i},
\end{aligned}
$$


where the permeability coefficient $\left(P_{i}\right)$ is equal to the product of the solubility coefficient of the permeance in the membrane $\left(S_{i}\right)$ and the diffusion coefficient $\left(D_{i}\right)$ of the permeance in the membrane.

As stated earlier, for pervaporation, the permeant concentration can be neglected when vacuum is used on the permeant side. Therefore, the overall mass transfer coefficient is estimated from the organic flux data obtained by varying feed concentration. Combining the above equations results in the resistance-in-series model that is typically applied to describe components transport by pervaporation $[54,55]$ :

$$
\frac{1}{K_{\mathrm{ov}}}=\frac{1}{k_{l}}+\frac{l}{P_{m}}
$$

or

$$
\frac{1}{Q_{\mathrm{ov}}}=\frac{1}{Q_{m}}+\frac{1}{Q_{l}}=\frac{l}{P_{m}}+\frac{\gamma p^{0}}{\rho_{l} k_{l}} .
$$

It is assumed that the diffusion coefficient remains constant and that there is negligible resistance offered by the vapor phase boundary layer. It is generally known that permeant pressures of $1-15$ Torr are a valid assumption. The liquid phase mass transfer coefficient for a driving force expressed in terms of vapor pressure $\left(Q_{l}\right)$ is related to the liquid phase mass transfer coefficient for a driving force in terms of concentration $\left(k_{l}\right)$ as follows:

$$
Q_{l}=\frac{\rho_{l}}{\gamma p^{0}} k_{l}
$$

The factor $\gamma p^{0} / \rho_{l}$ is the conversion factor from a concentration driving force to a partial vapor pressure driving force. It is useful to note this conversion factor since values for $Q_{l}$ are not generally available, and it is $k_{l}$ which is normally found in correlations which relate mass transfer coefficient to physical and hydrodynamic conditions. Similarly, to convert the overall mass transfer coefficient from a vapor pressure driving force $\left(Q_{\mathrm{ov}}\right)$ into a concentration driving force $\left(K_{\mathrm{ov}}\right)$,

$$
Q_{\mathrm{ov}}=\frac{\rho_{l}}{\gamma p^{0}} K_{\mathrm{ov}, l}
$$

Ganapathi-Desai and Sikdar [56] reported that flux increased linearly with increasing feed concentration as expected from (3). The slope of the line yields the overall mass transfer coefficient $\left(K_{\mathrm{ov}}\right)$. The determination of liquid side mass transfer coefficient $\left(k_{l}\right)$ is obtained using correlations. For laminar flow through a flat channel Leveque's correlation (15) is used. For turbulent flow (16) is used [57, 58].

Leveque's correlation for laminar flow in open channels is given as

$$
k_{l}=1.6\left[\frac{D_{i}}{d_{h}}\right][\mathrm{Re}]^{1 / 3}[\mathrm{Sc}]^{1 / 3}\left[\frac{d_{h}}{L}\right] .
$$

For turbulent flow through open channels, $k_{l}$ may be predicted as

$$
k_{l}=0.026\left[\frac{D_{i}}{d_{h}}\right][\mathrm{Re}]^{0.8}[\mathrm{Sc}]^{1 / 3}
$$

where $\operatorname{Re}=u \rho r d_{h} / \eta$ is Reynolds number, $L$ is length of cell, $d_{h}$ is hydraulic diameter, $A$ is cross-sectional area, $u$ is velocity, and $D_{i}$ is diffusivity.

Upon determination of $k_{l}$ from correlations, the resistance-in-series model is applied to the data $\left(K_{\mathrm{ov}}\right.$ and $k_{l}$ ) and membrane resistance (or permeability) is calculated from the intercept of the plot of $1 / K_{\mathrm{ov}}$ versus $1 / k_{l}$ from (11). This approach yields a quick measure of membrane permeability but cannot be relied upon if the $k_{l}$ estimates are approximate. Ganapathi-Desai and Sikdar [56] studied the separation of volatile organic compounds (VOCs) such as 1,1,1-trichloroethane (TCA) and trichloroethylene (TCE) from dilute aqueous solutions using composite membrane and reported the permeability by the above method as $5.7 \times 10^{-9}$ and $1.1 \times 10^{-8} \mathrm{~m}^{2} / \mathrm{s}$ for TCA and TCE, respectively. They reported the permeability values for other systems also.

3.1. Solution Diffusion Theory. The transport of gas, vapor, or liquid through a dense nonporous membrane is described as [59]

Permeability $(P)=$ solubility $(S) \times$ diffusivity $(D)$.

Solubility for gases is described by Henry's law. For ideal systems, solubility is independent of concentration and hence sorption isotherm is linear and concentration inside the polymer is proportional to applied pressure. For liquids, as they are not ideal, Henry's law is not applicable. In addition the affinity between liquid and polymer is much greater; hence, sometimes cross-linking is necessary to prevent polymer dissolution. High solubility implies high permeability as this influences diffusivity by making the polymer chains more flexible. Sorption isotherm is nonlinear and behavior is described by free volume models and Flory Huggins thermodynamics. Diffusion coefficients increase with the temperature, while sorption is usually exothermic [59-61]. For the effect of temperature on the permeability of organic compounds through a membrane, different results have been reported in the literature, in some cases permeability decreases with temperature $[60,61]$, in others, permeability increases with temperature [53], and for some cases permeability is unaffected by temperature within the range studied $[52,55]$.

Diffusivity depends on geometry of penetrant (as molecular size increases, diffusion coefficient decreases) and concentration. Dependence on size is determined by Stokes-Einstein equation, which is the relation between frictional resistance and the radius of the diffusing component

$$
f=6 \pi \eta r
$$

And diffusion coefficient is inversely proportional to frictional resistance as

$$
D=\frac{K T}{f} .
$$

Large molecules having ability to swell the polymer can have large diffusion coefficient. Diffusivity is determined by 
permeation method or time lag method. The amount of penetrant $\left(Q_{l}\right)$ passing through the membrane in time $t$ is given by

$$
Q_{l}=\frac{D c_{i}}{l}\left[t-\frac{l^{2}}{2 D}\right]
$$

Instead of $Q_{l}$, pressure $(p)$ can also be monitored and this plot of $p$ versus time $(t)$ will give time lag as intercept and permeability as slope from the steady state part of this permeation experiment. Since $P=S \times D$, hence $S$ can be found once $D$ and $P$ are known.

Alternatively, keeping the polymer in closed volume and applying pressure to the chamber can determine diffusivity. Due to sorption, the pressure decreases with time and equilibrium is reached.

\section{Parameters in Membrane Performance}

The effectiveness of a pervaporation membrane can be determined by mainly two parameters, namely, the separation factor and the permeant flux. The flux was determined by weighing the permeant mass and then dividing by the product of the interval time and membrane area. In dilute solutions, the fluxes are equal to the product of $D_{i} S_{i}$ for each component, where $D_{i}$ is the diffusion coefficient in the membrane material and $S_{i}$ is the sorption coefficient defined as

$$
S_{i}=\frac{w_{i, \mathrm{Memb}}}{w_{i, \mathrm{Feed}}},
$$

where $w_{i, \text { Memb }}$ and $w_{i \text {,Feed }}$ are the weight fractions of component $i$ in the membrane material and the liquid feed solution in solubility equilibrium with the membrane phase.

The solubility of a compound is the amount sorbed by the membrane under equilibrium conditions and hence a thermodynamic parameter, in contrast to the diffusivity $\left(D_{i}\right)$, which is a kinetic parameter quantifying the rate of permeation through the membrane. $D_{i}$ is depended on the geometry of the membrane as well as its state (glassy, rubbery, swollen, etc.). A small molecule will more easily diffuse through a membrane than a larger one.

Separation factor determines the overall separation performance of a membrane system. The value of separation factor may vary from unity to infinity. High value of separation factor specifies amplified selectivity. The separation factor $\alpha_{i}$ for a given compound $i$ is defined as the follows:

$$
\alpha_{i}=\frac{w_{i}^{\text {permeate }} /\left(1-w_{i}^{\text {permeate }}\right)}{w_{i}^{\text {feed }} /\left(1-w_{i}^{\text {feed }}\right)},
$$

where $w_{i}$ is the weight fraction of the compound $i$ in the feed $\left(w_{i}^{\text {feed }}\right)$ and in the permeance $\left(w_{i}^{\text {permeate }}\right)$.

Following the solution-diffusion mechanism, the basic transport equation for pervaporation can be written as

$$
J_{i}=\left[\frac{P_{i}}{l}\right]\left(x_{i} \gamma_{i} p_{i}^{\mathrm{sat}}-y_{i} p^{p}\right),
$$

where $P_{i}$ is the membrane permeability, which is a product of diffusivity and solubility coefficients, $l$ is the membrane thickness, $y_{i}$ is the permeant mole fraction, and $p^{p}$ is the permeant pressure. The term $\left[P_{i} / l\right]$ is known as permeance that can be determined by rearranging the above equation:

$$
\left[\frac{P_{i}}{l}\right]=\frac{J_{i}}{\left(x_{i} \gamma_{i} p_{i}^{\text {sat }}-y_{i} p^{p}\right)} .
$$

The ideal membrane selectivity $\beta$ is defined as the ratio of the permeability coefficients or the permeances:

$$
\beta_{i / j}=\frac{P_{i}}{P_{j}} .
$$

Overall performance of the membrane was evaluated in terms of pervaporation separation index (PSI), as given in the following [62]:

$$
\mathrm{PSI}=J(\alpha-1),
$$

where $J$ is permeation flux $\left(\mathrm{kg} / \mathrm{m}^{2} \mathrm{~h}\right)$; when $\alpha=1$, no separation occurs; PSI of zero means either zero flux or zero separation. Table 2 and Figures 4-6 summarize the performance parameters of different types of membranes for several systems obtained in the pervaporation studies of research articles. It presents the values of important parameters including permeation flux and selectivity of membrane at different operating temperatures.

4.1. Effect of Membrane Thickness. According to Fick's equation and the solution-diffusion model, permeability of a penetrant through a membrane should be independent of membrane thickness, but the flux is inversely proportional to membrane thickness [63]. Hasanoglu et al. [64] studied hydrolysis reaction of ethyl acetate (ethyl acetate (EAc), water, ethanol (EOH), and acetic acid (AsAc)) using polydimethylsiloxane (PDMS) and discussed the effect of membrane thickness. $250 \mu \mathrm{m}$ and $300 \mu \mathrm{m}$ membranes thickness were employed. It was found that fluxes through $250 \mu \mathrm{m}$ membranes are higher than those through the $300 \mu \mathrm{m}$ membranes.

Hyder et al. [65] studied the influence of selective layer thickness on separation factors of dehydration of ethanolwater mixture using poly(vinyl alcohol) and poly(sulfone) (PVA-PSf) cross-linked composite membrane with varying selective PVA layer thickness and concluded that, with a change in thickness from 52 to $4 \mu \mathrm{m}$ (92\% decrease), the selectivity change was not significant (only $17 \%$ decrease), compared to the change in flux (193\% increase) that was dependent on the bulk thickness of the membrane.

Raisi and Aroujalian [66] investigated the effect of membrane thickness on the performance behavior of the pervaporation membrane PDMS (polydimethylsiloxane) and POMS (polyoctylmethylsiloxane) in the binary and ternary model solution of pomegranate aroma compounds. It was observed that results were in agreement with the fact that the permeation rate is inversely proportional to membrane thickness because permeation resistance enhances as membrane thickness increases. 
TABLE 2: Overview of membrane performance parameters of different pervaporation systems.

\begin{tabular}{|c|c|c|c|c|c|}
\hline \multirow[b]{2}{*}{ System } & \multirow[b]{2}{*}{ Membrane } & \multicolumn{3}{|c|}{ Parameters } & \multirow[b]{2}{*}{ Reference } \\
\hline & & $\begin{array}{l}\text { Temperature } \\
\left({ }^{\circ} \mathrm{C}\right)\end{array}$ & $\begin{array}{c}\text { Flux } \\
\left(\mathrm{kg} / \mathrm{m}^{2} \mathrm{~h}\right)\end{array}$ & Selectivity & \\
\hline Water/isobutyl acetate & PDMS & 70 & 4.429 & 1.421 & {$[47]$} \\
\hline Water/isobutyl acetate & PERVAP 1201 & 70 & 0.712 & 686.5 & [47] \\
\hline Water/ethyl acetate & Hydrophilic & 40 & $\begin{array}{c}0.448 \\
\left(\mathrm{~mol} / \mathrm{m}^{2} \mathrm{~h}\right)\end{array}$ & - & [109] \\
\hline Water/ethyl acetate & Hydrophobic & 40 & $\begin{array}{c}7.505 \\
\left(\mathrm{~mol} / \mathrm{m}^{2} \mathrm{~h}\right)\end{array}$ & - & [109] \\
\hline Water/ethyl lactate & $\begin{array}{l}\text { Glutaral cross-linked chitosan (GCCS)/carbomer } \\
(\mathrm{CP}) / \text { polyacrylonitrile (PAN) }\end{array}$ & 80 & 1.247 & 256 & {$[46]$} \\
\hline Water/ethyl lactate & Glutaral cross-linked gelatin (GCGE)/PAN & 80 & 1.08 & 298 & {$[46]$} \\
\hline Water/ethyl lactate & $\begin{array}{l}\text { Glutaral cross-linked hyaluronic acid } \\
\text { (GCHA)/hydrolysis modification (HM)-PAN) }\end{array}$ & 80 & 1.634 & 233 & {$[46]$} \\
\hline Water/ethyl oleate & PERVAP 1000 & 25 & 0.215 & 120 & {$[110]$} \\
\hline Water/n-butanol & PVA/PES & 75 & 0.14 & 135 & {$[48]$} \\
\hline n-Butyl acetate/methanol & PERVAP 2255-50 & 41 & - & 3.5 & [111] \\
\hline Isobutyl acetate/water & Cross-linked PDMS & 60 & 3.7 & 1.4 & {$[95]$} \\
\hline Water/ethanol & Polyvinyl alcohol & $90-100$ & $0-2$ & $50-2000$ & {$[112]$} \\
\hline Water/ethanol & Polyamide- 6 & 80 & 1.15 & 2 & {$[113]$} \\
\hline Water/dioxane & Polyamide-6 & 35 & 0.04 & 45 & {$[114]$} \\
\hline Water/acetic acid & Polyamide-6/PAA & 15 & 0.005 & 82 & {$[115]$} \\
\hline Water/isopropanol & PESS Li+ & 25 & 0.087 & 40 & {$[116]$} \\
\hline Water/isopropanol & PESS K+ & 25 & 0.026 & 60 & [116] \\
\hline Acetone/water & Polypropylene & 116 & $0.1-1.2$ & 3 & {$[117]$} \\
\hline Isopropanol/water & Silicone rubber & 25 & $0.03-0.11$ & $9-22$ & {$[118]$} \\
\hline Butanol/water & Silicone rubber & 30 & $<0.035$ & $45-65$ & {$[119]$} \\
\hline Butyl acetate/water & PDMS & 50 & 0.55 & 370 & {$[120]$} \\
\hline Ethanol/water & Zeolite NaA & 95 & 3.35 & 5100 & {$[121]$} \\
\hline Water/acetic acid & Pervatech & 75 & 2.5 & 150 & {$[122]$} \\
\hline Water/isopropanol & Pervatech & 100 & 4.0 & 250 & {$[122]$} \\
\hline Ethanol/water & Polyacrylonitrile & 70 & 0.03 & 12500 & {$[123]$} \\
\hline Ethanol/water & Polyvinyl alcohol & 70 & 0.38 & 140 & {$[123]$} \\
\hline Ethanol/water & Polyhydrazide & 70 & 1.65 & 19 & [123] \\
\hline Methanol/isopropanol & Polypyrrole & 58 & 0.004 & 2 & {$[124]$} \\
\hline Water/n-butanol & PVA membrane & $70-90$ & $0.154-0.184$ & $12.2-16.5$ & {$[125]$} \\
\hline Water/n-butyl acetate & PVA membrane & $70-90$ & $0.15-0.196$ & $432-441$ & {$[125]$} \\
\hline Water/acetic acid & PVA membrane & $70-90$ & $0.176-0.192$ & $9.0-10.8$ & {$[125]$} \\
\hline Water/methanol & CS-TEOS & $60-80$ & $0.005-0.29$ & $450-1150$ & [73] \\
\hline Ethanol/water & Tri-n-octylamine (liquid membrane) & 54 & 0.0598 & 100 & {$[75]$} \\
\hline Ethyl acetate/water & Surface modified alumina membrane & 40 & 0.254 & $66.9-78.9$ & {$[76]$} \\
\hline Ethyl propionate/water & Surface modified alumina membrane & 40 & 0.343 & $106.5-97.3$ & {$[76]$} \\
\hline Ethyl butyrate/water & Surface modified alumina membrane & 40 & 0.377 & $120.5-122.8$ & {$[76]$} \\
\hline Water/ethanol & Modified porous glass & 79 & 0.1 & 1630 & {$[126]$} \\
\hline Water/ethanol & Polyimide & 75 & 0.01 & 850 & {$[127]$} \\
\hline
\end{tabular}




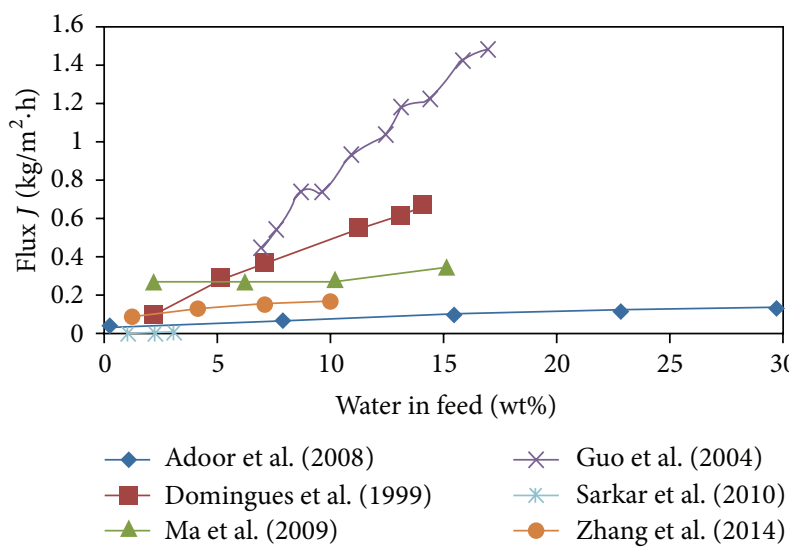

Figure 4: Effect of feed water concentration (wt\%) on flux of waterorganic pervaporation system.

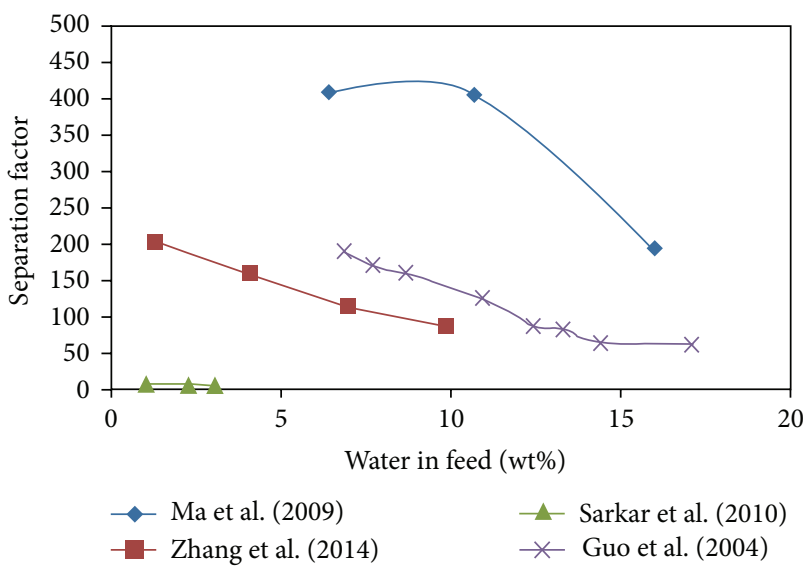

FIGURE 5: Effect of feed water concentration (wt\%) on separation factor of water-organic pervaporation system.

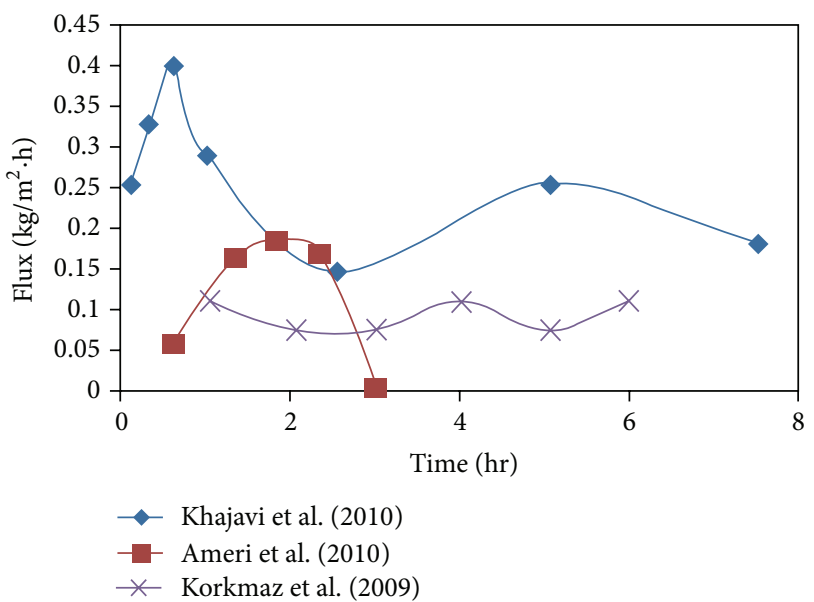

FIGURE 6: Obtained trend of flux with time for different pervaporation systems.
4.2. Effect of Temperature. Temperature has a significant effect on the transportation rate. The effect of temperature can be expressed by an Arrhenius type function. Since $P=S \times D$, both $S$ and $D$ contribute to the effect of temperature. For small noninteractive gases, $D$ is the more dominating, as $S$ does not change much with temperature. For the larger molecules, the situation is more complex since two effects, diffusion and solubility, are opposing, and further both are concentration dependent.

$S$ dependence on temperature can be described as

$$
S=S_{o} \exp \left(-\frac{\Delta H_{s}}{R T}\right),
$$

where $S_{o}$ is the temperature-independent constant and $\Delta H_{s}$ is heat of solution. Similarly temperature effect on diffusion is described as

$$
D=D_{o} \exp \left(-\frac{E_{d}}{R T}\right)
$$

where $D_{o}$ is the temperature-independent constant and $E_{d}$ is activation energy for diffusion or it is a preexponential factor. Using $P=S \times D$ and using the above expression for $S$ and $D$, we get

$$
P=D_{o} S_{o} \exp -\left(\frac{\Delta H_{s}+E_{d}}{R T}\right)=P_{o} \exp -\left(\frac{E_{p}}{R T}\right) .
$$

Chang et al. [67] represent the temperature dependence of flux using the following relationship:

$$
\begin{aligned}
J_{w}(T, P)= & J_{w}\left(T^{o}, P^{o}\right) \exp \left[\left(\frac{E_{w}}{R}\right)\left(\frac{1}{T^{o}}-\frac{1}{T}\right)\right] \\
& \cdot \frac{R T \ln \left(x_{w} \gamma_{w} P_{w}^{o} / y_{w} P\right)}{R T \ln \left(x_{w} \gamma_{w} P_{w}^{o} / y_{w} P^{o}\right)},
\end{aligned}
$$

where $J_{w}\left(T^{o}, P^{o}\right)$ is the water flux measured at a feed side temperature of $T^{o}$ and permeant side pressure of $P^{o}$.

The term on the influence of permeant pressure on water flux in (30) is derived from the fact that the driving force for transport originates from the difference in chemical potential between feed and permeance in the pervaporation [68]. The difference in chemical potential can be approximated as a difference in partial vapor pressures of the permeating component in the liquid feed and the gaseous permeance. Empirical equations for partial water permeation flux and permeation water composition are given by the following equations:

$$
\begin{aligned}
J_{w} & =3.935 C_{w}^{f}, \\
C_{w}^{p} & =\frac{12 C_{w}^{f}}{0.055+12.84 C_{w}^{f}-7.7 C_{w}^{f^{2}}} .
\end{aligned}
$$

The data on saturation vapor pressure required for calculating (32) were obtained by using the coefficients as tabulated by Daubert and Danner [69] and the activity coefficient by using the coefficients for the Van Laar equation as tabulated by Gmehling and Onken [70]. The equations and coefficients are given in the following equations: 


$$
\begin{aligned}
P_{w}^{o} & =\exp \left(A+\frac{B}{T}+C \ln T+D T^{E}\right), \\
\qquad A=7.3649 \times 10, B=-7.2582 \times 10^{3}, C=-7.3037, D=4.1653 \times 10^{-6}, E=2, & \\
\ln \gamma_{w} & =A_{12}\left[\frac{A_{21}\left(1-x_{w}\right)}{\left\{A_{12} x_{w}+A_{21}\left(1-x_{w}\right)\right\}}\right]^{2}, \quad A_{12}=1.7769, A_{21}=0.94,
\end{aligned}
$$

where $P_{w}^{o}$ and $\gamma_{w}$ are the saturated vapor pressure and the activity coefficient of water, respectively, and $x_{w}$ is the mole fraction of water in an ethanol/water mixture.

Effect of temperature on membrane mass transfer coefficient $\left(k_{l}\right)$ can be derived from changes in the physical properties of the solution, mainly its viscosity. For the same flow rate, the Reynolds number increases sharply with temperature. From $30^{\circ} \mathrm{C}$ at a constant liquid flow rate, the Reynolds number increased from 7930 to 11469 at $50^{\circ} \mathrm{C}$ and to 15573 at $70^{\circ} \mathrm{C}$ in the studies by Oliveira et al. [54] Their studies were on monochlorobenzene (MCB) transport using silicone rubber (70\% polydimethylsiloxane (PDMS) $+30 \%$ silica filler) tubing as membrane.

Burshe et al. [71] studied the effect of temperature on flux and selectivity of water in glycerine-water mixtures using Nafion (NA), cellulose triacetate (CA), carboxylated polyvinyl chloride (CPVC), and polyimide and polyethersulfone (PES) membranes. Temperature was varied from $30^{\circ} \mathrm{C}$ to $70^{\circ} \mathrm{C}$. Increasing temperature was found to increase flux. Though amount sorbed decreased with temperature yet, this is offset by an increase in the diffusion coefficient of the solute because of increased temperature. NA has the lowest energy of activation for diffusion and hence efficiently transports water through it. Increasing temperature however decreases selectivity. The reason behind this is that the thermal motion of polymer chains randomly produces free volumes through which permeating molecules can diffuse. With increasing temperature, thermal agitation increases, thus enlarging the diffusive free volume. Thus, more solute can diffuse through the membrane. At water content $>60 \%$ very little difference in selectivity was observed at all temperatures.

Domingues et al. [44] pointed out that the flux is practically linear for small variations in the water concentration and that it increases with an increase in temperature and membrane selectivity for water remains constant and equal to $96 \%$. Guo et al. [72] reported that water flux increases with an increase in temperature. The reason is that increase in motions of the polymer chains thermally induced and the expansion of the free volume. In addition, the increased thermal motions of the permeant molecules also promote their diffusion. However, water permeance does not increase with an increase in temperature. The relatively negative dependence of water permeances on temperature may arise from the fact that permeance is defined as permeant flux divided by permeant driving force. The driving force combines two temperature-dependent factors, $\gamma_{i}$ and $p_{\text {sat }}$, which are external factors outside the membrane. The values of water activity coefficients of different butanol water systems (1-butanol/water; 2-butanol/water; isobutanol/water; and tert-butanol/water) are quite close at different temperatures for each of four butanol systems. Thus, $p_{\text {sat } i}$ plays a more important role than the water activity coefficient in these four systems. The higher temperature results in a higher $p_{\text {sat } i}$, a larger denominator, and consequently a smaller permeance.

Ma et al. [73] presented the effect of operating temperature ranging from $60^{\circ} \mathrm{C}$ to $80^{\circ} \mathrm{C}$ on the pervaporation properties of the CS-TEOS membrane. The reaction system was lactic acid-ethanol and Amberlyst 15 ion exchange resin was used as a catalyst. Total flux increased notably, while the separation factor decreased with increasing temperature. When operating temperature is increased, vapor pressure of permeating components in the upstream side of the membrane increases. Vapor pressure difference between the upstream and downstream side of the membrane enhanced the transport driving force. Moreover, increasing temperature brought about higher molecular diffusivity [74]; therefore, the mass transport was faster, and the total flux increased. In addition, as temperature is increased, polymer chains became more flexible and accommodated larger available free volume of the polymer matrix for diffusion, which allowed easier water and ethanol transfer across membrane and eventually the selectivity decreased.

Thongsukmak and Sirkar [75] studied alcohol-water separation for feed alcohol concentrations of $5-10 \%$ in the presence of a small amount of n-butanol in the feed varying between 0.5 and $2.5 \mathrm{wt} \%$ over a feed temperature range of $30-$ $54^{\circ} \mathrm{C}$. In single organic solvent species in solution, three feed concentration levels, the values for $1.5,5$, and $10 \mathrm{wt} \%$ were taken. As the temperature was increased from 25 to $54^{\circ} \mathrm{C}$, the n-butanol-water selectivity went up from 60 to as high as 162 at $54^{\circ} \mathrm{C}$; the permeant mass flux of n-butanol reached $11.0 \mathrm{~g} /\left(\mathrm{m}^{2} \mathrm{~h}\right)$ at $54^{\circ} \mathrm{C}$ (for a $\mathrm{n}$-butanol wt\% of 1.5 in feed). In mixtures of n-butanol and ethanol, the selectivity and mass flux of solvents were increased significantly at elevated temperatures. For a constant air flow rate, the beneficial effect of increasing temperature on the mass transfer of monochlorobenzene (MCB) across the membrane silicone rubber (70\% polydimethylsiloxane (PDMS) + 30\% silica filler) tubing ( $3.0 \mathrm{~mm}$ i.d. with $1 \mathrm{~mm}$ wall thickness) was reflected in an increase of the MCB concentration in the air stream leaving the membrane module [54]. For an increase in temperature from $30^{\circ} \mathrm{C}$ to $50^{\circ} \mathrm{C}$, the $\mathrm{MCB}$ concentration in the gas outlet of the membrane module (at standard temperature and pressure) increased by a factor of 1.3 , from 3.2 to $4.2 \mathrm{gm}^{-3}$. From 30 to $60^{\circ} \mathrm{C}$, the increase was by a factor of 1.6 .

Song et al. [76] studied the pervaporation of ester (ethyl acetate, EA; ethyl propionate, EP; ethyl butyrate, EB) with 
hydrophobic membranes. Effect of temperature $\left(30-50^{\circ} \mathrm{C}\right)$ on different esters (ethyl acetate, EA; ethyl propionate, EP; and ethyl butyrate, EB) was studied. For EB and water permeation through a hydrophobic alumina membrane, the $E_{a}$ values are 34.1 and $45.7 \mathrm{~kJ} / \mathrm{mol}$ for $\mathrm{EB}$ and water, respectively, whereas their corresponding $E_{p}$ values are -2.2 and $-5.1 \mathrm{~kJ} / \mathrm{mol}$. The negative value of $E_{p}$ for $E B$ means that the increasing rate of ester flux reduces with increasing temperature. Activation energy of penetrant increased as the penetrant size increased in the order: $\mathrm{EA}<\mathrm{EP}<\mathrm{EB}$. Activation energy $\left(E_{a}\right)$ is the sum of the activation energy of diffusion $\left(E_{D}\right)$ and the enthalpy of sorption $(\Delta H)$. While $E_{D}$ is usually positive, $\Delta H$ is negative for the exothermic sorption process. When the positive $E_{D}$ dominates over the negative $\Delta H$, the positive value of $E_{a}$ occurs, indicating that the membrane permeability coefficient increases with increasing temperature [60]. In this study, the activation energy $\left(E_{p}\right)$ of esters was negative and that of water was positive values. The ester flux decreased and water flux increased with increasing temperature, which shows that the activation energy of sorption $(\Delta H)$ dominates over diffusion. The activation energy of $\mathrm{EB}$ was greater than EA and EP, which means that permeation flux of EB was most sensitive to the temperature change. It was observed that all ester compound and water fluxes increased exponentially with temperature. The reason for this is the flux expression which is expressed as follows:

$$
J_{i}=K_{i}\left(C_{i} x_{i}^{\mathrm{feed}} p_{i}^{o}\left(T^{\mathrm{feed}}\right) C_{2}\right) .
$$

Since vapor pressure $\left(p_{i}^{o}\right)$ increases with increasing temperature, this results in the increase of flux $\left(J_{i}\right)$. The fluxes of EB increased with increasing temperature, and the concentration of EB in permeance decreased with increasing temperature. This result might be explained by the negative value of $E_{p}$ for ester as described earlier. All esters (EA, $\mathrm{EP}$, and $\mathrm{EB}$ ) exhibited similar behavior regarding permeant concentration with feed temperature.

Transport of volatile organic compounds (VOCs) such as 1,1,1-trichloroethane (TCA) and trichloroethylene (TCE) from dilute aqueous solutions through composite membrane constructed on a porous ceramic support from a block copolymer of styrene and butadiene (SBS) was studied by Ganapathi-Desai and Sikdar [56]. An increase in feed temperature causes changes in the feed viscosity and VOC diffusion coefficients and yields higher fluxes for all components. Arrhenius plot of flux versus temperature was used to calculate the activation energy for the transport of the VOCs through the SBS composite membrane. These activation energies for TCA and TCE were found to be 4.4 and $5.3 \mathrm{kcal} / \mathrm{mol}$, respectively. In an earlier work by Dutta and Sikdar [77], activation energy of $5.6 \mathrm{kcal} / \mathrm{mol}$ was reported for TCA transport through the SBS membrane.

4.3. Effect of Feed Concentration. D can be related as an exponential function of volume fraction of penetrant as

$$
D=D_{o} \exp (\gamma \phi),
$$

where $\phi$ is the volume fraction of penetrant, $\gamma$ is exponential constant (plasticizing constant, indicating the plasticizing action of the penetrant on segmental motion), and $D_{o}$ is the diffusion concentration at zero concentration. $D_{o}$ is related to molecule size and $D_{o}$ is large for small molecules and small for large molecules. However, $\phi$ and $\gamma$ are greatly dominating factors as they are in exponential terms. For gases that hardly show any interaction with polymer, $\gamma=0$; hence $D=D_{o}$.

Free volume theory describes the concentration dependence of the diffusion coefficient. Polymer has two states, namely, glass and rubber. Below glass transition temperature, there is glassy state and mobility of chain segment is limited. Above $T_{g}$, mobility increases, frozen microvoids no longer exist, and the number of the parameters changes, one of which is the specific volume, expressed as

$$
V_{f}=V_{T}-V_{o},
$$

where $V_{o}$ is the volume occupied by molecules at $0 \mathrm{~K}$ (estimated by group contribution method).

Fractional volume is defined as

$$
v_{f}=\frac{V_{f}}{V_{T}},
$$

where $v_{f}$ or $V_{T}$ is obtained from polymer density. For glass polymer, the fractional free volume is 0.025 and hence below $T_{g}$ it is constant and is equal to $v_{f, T_{g}}$. Above $T_{g}$

$$
v_{f}=v_{f, T_{g}}+\Delta \alpha\left(T-T_{g}\right),
$$

where $\Delta \alpha$ is the difference between the value of thermal expansion coefficient above $T_{g}$ and below $T_{g}$. Molecule can diffuse only if there is sufficient space or free volume. If the penetrant size increases the amount of free volume must also increase. The probability of finding hole whose size exceeds the critical value is proportional to $\exp \left(-B / v_{f}\right) ; B$ is local free volume needed for a given penetrant; $v_{f}$ is fractional free volume. Thus, the mobility of penetrant depends on the probability of finding a hole of appropriate size. Mobility can be related to thermodynamic diffusion coefficient:

$$
D_{T}=R T A_{f} \exp \left[-\frac{B}{v_{f}}\right]
$$

where $A_{f}$ is dependent on the size and shape of penetrant molecule and $B$ is in relation to minimum local free volume necessary to allow a displacement. Thus, from the above equation, $D$ increases as temperature increases and $D$ decreases as the size of penetrant molecule increases since $B$ increases.

For noninteracting systems, $A_{f}$ and $B$ are independent of the polymer type; hence diffusivity of given gas molecule can be determined from density measurement alone. If $A_{f}$ and $B$ are function of the polymer type, $v_{f}$ as function of both temperature and concentration in needed

$$
v_{f}(\phi, T)=v_{f}(0, T)+\beta(T) \phi,
$$

where $v_{f}(0, T)$ is the free volume of the polymer at temperature $T$ in the absence of penetrant; $\beta(T)$ is constant 
characterizing the extent to which the penetrant contributes to the free volume; and $\phi$ is the volume fraction of penetrant.

Diffusion coefficient at zero penetrant concentration can be given as

$$
D_{0}=R T A_{f} \exp \left[-\frac{B}{v_{f}(0, T)}\right] .
$$

Combining the equations,

$$
\ln \frac{D_{T}}{D_{0}}=\left[\frac{B}{v_{f}(0, T)}-\frac{B}{v_{f}(\phi, T)}\right]
$$

or

$$
\left[\ln \frac{D_{T}}{D_{0}}\right]^{-1}=\left[\frac{v_{f}(0, T)}{B}-\frac{v_{f}(0, T)^{2}}{B(T) B \cdot \phi}\right] .
$$

Thus the LHS is related linearly to $\phi^{-1}$. The relationship between measured diffusion coefficient $(D)$ and thermodynamic diffusion coefficient $\left(D_{T}\right)$ is

$$
D_{i}=D_{T}\left[\frac{d \ln a_{i}}{d \ln \phi_{i}}\right] \text {. }
$$

The factor in bracket is obtained from Flory Huggins thermodynamics. The activity of penetrant inside the polymer is

$$
\ln a_{i}=\ln \left(\frac{p_{i}}{p_{o}}\right)=\ln \phi_{i}+\left(1-\frac{v_{i}}{v_{p}}\right) \phi_{p}+\chi \phi_{p}^{2},
$$

where $\chi$ is the interaction parameter; if $\chi$ is greater than 2 , the interaction is small; if $\chi$ lies between 0.5 and 2, strong interaction exists and high permeability is expected. Thus,

$$
\left[\frac{d \ln a_{i}}{d \ln \phi_{i}}\right]=1-\left(2 \chi+1-\frac{v_{i}}{v_{p}}\right) \phi+2 \chi \phi_{p}^{2} .
$$

Component diffuses not a single molecule but in dimmer or trimmer form. Size of diffusing component increases with the diffusion coefficient decreases. The presence of clustered component can be determined by the cluster integral $G_{11}$ (Zimm Lindbergh theory):

$$
\frac{G_{11}}{V_{1}}=\left(\frac{1}{\phi_{1}}-1\right)\left[\frac{d \ln a_{i}}{d \ln \phi_{i}}\right]-\frac{1}{\phi_{1}},
$$

where $V_{1}$ is the molar volume. For an ideal system, $\left[d \ln a_{i} / d \ln \phi_{i}\right]=1$; hence LHS of the above equation is 1 and hence no clustering is there. If LHS is greater than -1 , clustering will occur.

Chang et al. [67] studied the pervaporation of ethanol in the pilot plant and found that the water content in permeance is still high even with low water content in the feed. Membrane selectivity was found to be hardly altered by permeant pressure change. Permeation fluxes increase linearly with the water content in the feed and decrease with permeant pressure. Temperature influence is described by Arrhenius law and activation energy was found to be $E_{w}=$ $7.84 \mathrm{kcal} / \mathrm{mol}$.
Burshe et al. [71] studied the effect of water concentration on flux and selectivity of water in glycerine-water mixtures using Nafion (NA), cellulose triacetate (CA), carboxylated polyvinyl chloride (CPVC), polyimide (PI), and polyethersulfone (PES) membranes. Increasing water in feed increases flux of water and following trend was observed NA $>$ CA $>$ $\mathrm{PES}>\mathrm{CPVC}>\mathrm{PI}$. The reason for this is the plasticization of NA membrane because of increased water concentration in the membrane phase, which increases the free volume and results in increasing the sorption. Selectivity decreases with an increase of water in the feed in the trend $\mathrm{PES}>\mathrm{PI}>\mathrm{NA}>$ $\mathrm{CA}>\mathrm{CPVC}$.

Guo and $\mathrm{Hu}$ [78] studied on ethanol-water transport in novel silicone copolymer consisting of PDMS segments and ladder-like phenylsilsesquioxane segments and found that the concentration of ethanol in the permeance is always higher than that in the corresponding feed. The separation factor decreases as the ethanol concentration in feed increases. High separation factor can be obtained for the separation of dilute aqueous solution of ethanol through the membrane. The flux of ethanol increases proportionally with increasing ethanol concentration in the feed, whereas the flux of water is almost constant for various feed compositions. The magnitude of separation factor and flux for the pervaporation increases in the following order: methanol $<$ ethanol $<2$ propanol $<$ acetone $<$ THF. This order just corresponds with the decreasing order of the solubility parameters of these organic components.

Wolińska-Grabczyk et al. [79] employed three types of membranes, PUU-PEs-1, PUU-PEs-2, and PU-PEt-1 for separation of both high and low concentrations of benzene in benzene/cyclohexane mixture. Polyester-based polyurethanes (PUU-PEs-1, PUU-PEs-2) exhibited an acceptable selectivity and permeability and excellent stability to separate benzene/cyclohexane azeotropic mixture. Replacement of the polyester macrodiol with the polyether one (PU-PEt-1) resulted in a membrane material with a much higher permeability accompanied still by a lower selectivity. The increase in the flux value is commonly accompanied by the loss of the membrane selectivity. For the separation of $\mathrm{MTBE} / \mathrm{MeOH}$ model mixture containing 15 mass $\%$ of $\mathrm{MeOH}$, the obtained membranes were preferentially permeable to $\mathrm{MeOH}$ over MTBE. Excellent separation capability $(100 \%$ of $\mathrm{MeOH}$ in permeance) is shown by PU-PEt membrane prepared from polyether-based polyurethane. The substitution of the polyether in a polyurethane soft segment by the polyester resulted in more permeable membrane with slightly less separation ability. For the removal of benzene and chloroform from water, PU-PD-1 polyurethanes exhibit excellent selectivity. Structural modifications concerning the application of the polyether rather than the polydiene macrodiol (PU-PEt-1 versus PU-PD-2) led to some improvement of the membrane permeability, however, at the expense of its selectivity.

Guo et al. [72] found that the partial water flux increases rapidly with feed water concentration. The selective layer of the composite membrane is made of polyvinyl alcohol (PVA) with hydroxyl substituted groups. Thus, it has a high polarity and experiences a strong interaction with water 
through hydrogen bonding. At higher feed water concentrations, there are greater numbers of water molecules in contact with the selective layer of the membrane. Therefore, more water molecules are sorbed into the membrane, which causes a greater degree of swelling in the top layer of the membrane. Consequently, more water molecules can pass through the water-swollen membrane and water permeation flux increases as the feed water content increases. The percentage of increment for water permeance with increasing feed water content is slightly lower than that of water flux. Presence exhibits more accurate permeant-specific transport properties with feed concentration because it has significantly decoupled the effect of fugacity difference as the driving force from the overall membrane transport. Butanol concentration in the permeance decreases with an increase in feed water concentration for the 2-butanol, isobutanol, and tert-butanol/water systems while the trend is opposite to the 1-butanol/water system. 1-Butanol presents the highest flux compared with other alcohols because of the strongest affinity between 1-butanol and membrane and the highest linearity of 1-butanol molecular structure.

Ma et al. [73] studied the effect of water content in the feed varying from $2 \mathrm{wt} \%$ to $15 \mathrm{wt} \%$ in the esterification studies on lactic acid ethanol system using Amberlyst 15 ion exchange resin. With the increase of water content in the feed, the total flux increased from $271 \mathrm{~g} /\left(\mathrm{m}^{2} \mathrm{~h}\right)$ to $352 \mathrm{~g} /\left(\mathrm{m}^{2} \mathrm{~h}\right)$, while the separation factor decreased from 1380 to 268. Degree of swelling value of the CS-TEOS membrane increased with increasing water content in the feed, leading to the reduction of mass transfer resistance and the acceleration of diffusion velocity for components in the membrane. Meanwhile, the size of voids in the membrane became larger and larger with increasing $D S$ value; ethanol molecules won more chance to pass through these voids, which resulted in the decrease of separation factor.

In the hydrolysis reaction of ethyl acetate (ethyl acetate $(\mathrm{EAc})$, water, ethanol (EOH), and acetic acid (AsAc)) using polydimethylsiloxane (PDMS) membrane, Hasanoglu et al. [64] found that, with the increase in the ethyl acetate concentration in the feed, the ethyl acetate fluxes increase. While the ethyl acetate concentrations increase from 1 to $3 \mathrm{wt} \%$, total fluxes (summation of partial fluxes) change in the range of $79-307 \mathrm{~g} / \mathrm{m}^{2} \mathrm{~h}$ for the quaternary mixtures. This phenomenon was explained related to the plasticizing effect of the organic molecules. As the EAc concentration in the feed increases, membrane swells more, and the polymer chains become more flexible, thus decreasing the energy required for the diffusive transport through the membrane. Acetic acid and ethanol permeate through the PDMS membrane in very small quantities. For the mixtures, which have the same EAc concentrations, an increase in ethanol concentration in feed yields higher partial fluxes of ethanol while the acetic acid flux is not much affected by feed concentration of acetic acid. The reason for this is that the three different feed mixtures having 3\% EAc concentrations have different partial fluxes of EAc indicating the effects of mutual interactions of each component on the fluxes. The total fluxes increase with increasing EAc/water ratio due to the hydrophobicity of the membrane and the affinity of the membrane to the EAc molecules. An increase in EAc/organic ratio in feed yields a decrease in EAc/organic selectivity. This is due to the reason that increases of ethyl acetate amount in the feed mixture, in which PDMS is more permeable causes, the membrane to swell. Therefore, the amount of other soluble components dissolved in the membrane increases due to the presence of ethyl acetate.

Thongsukmak and Sirkar [75] studied alcohol-water separation for feed alcohol concentrations of $5-10 \%$ in the presence of a small amount of $n$-butanol in the feed varying between 0.5 and $2.5 \mathrm{wt} \%$ over a feed temperature range of $30-54^{\circ} \mathrm{C}$. In single organic solvent species in solution, three feed concentration levels, the values for 1.5, 5, and $10 \mathrm{wt} \%$ are taken. The selectivity of ethanol goes up to 38 at a feed temperature of $54^{\circ} \mathrm{C}$ and $10.0 \mathrm{wt} \%$ ethanol in feed. Higher feed ethanol concentration results in a higher selectivity and mass flux due to a higher driving force for the pervaporation of ethanol through the liquid membrane. In the studies on mixtures of n-butanol and ethanol, the selectivity and mass flux of ethanol got higher when the concentration of ethanol was higher in the feed. This is due to the higher concentration in the feed that provided a higher driving force via the increase in the ethanol effective partial pressure. The mass flux of ethanol obtained for $10 \mathrm{wt} \%$ ethanol in feed obtained was $16.2 \mathrm{~g} /\left(\mathrm{m}^{2} \mathrm{~h}\right)$, which is considerably higher than the flux for the experiment without n-butanol added to the feed (by $73 \%$ ). The selectivity of ethanol went up to 66 for the mixture of $10 \mathrm{wt} \%$ ethanol with $1 \mathrm{wt} \% \mathrm{n}$-butanol in the feed at $54^{\circ} \mathrm{C}$; this is much higher than the highest ethanol selectivity obtained with single species solution of ethanol at $54^{\circ} \mathrm{C}$.

Pervaporation of esters with hydrophobic membrane was studied by Song et al. [76]. Permeation fluxes of esters were found to increase linearly as feed concentration increased while the permeation flux of the water was not affected by ester concentration in the feed. The fluxes can be expressed as follows:

$$
J_{i}=K_{i}\left(C_{i} x_{i}^{\text {feed }} p_{i}^{o}\left(T^{\text {feed }}\right)-C_{2}\right) .
$$

At a given temperature, the permeation flux of ester is a function of $k_{i}$, saturation pressure of ester $\left(p_{i}^{o}\right)$, and molar fraction of ester $\left(x_{i}^{\mathrm{feed}}\right) . k_{i}$ increases with the feed concentration owing to the increasing solubility coefficient $\left(S_{i}\right)$ and diffusion coefficient $\left(D_{i}\right)$. As expected from the above equation, ester flux increased relatively linearly with increasing molar fraction in feed $\left(x_{i}^{\text {feed }}\right)$. In the case of water flux, however, it might be inferred from the equation that water flux at a given temperature did not depend on ester concentration in the feed because the molar fraction of water in the feed $\left(x_{w}^{\text {feed }}\right)$ remained virtually constant in the range of dilute ester concentration. That is why the permeation flux of water was not affected by ester concentration. The total flux increased with increasing ester concentration in the feed due to the high flux of ester.

As the feed ester concentration was increased from 0.15 to $0.60 \mathrm{wt} \%$, the separation factor of $\mathrm{EA}$ at $40^{\circ} \mathrm{C}$ increased from 66.9 to 78.9. However, the separation factors of EP and EB were not much affected by feed concentration, which was 
in the range of 106.5-97.3 and 120.5-122.8, respectively. The separation factors of PDMS membrane are higher than those of this study; separation factor of EA with PDMS GFT is 85.0145.0; PDMS GFTz 254.0; PDMS DC 368.0. Those of EP and EB with PDMS are 79.0-171.2 and 96-196.3, respectively.

Ganapathi-Desai and Sikdar [56] in their studies on SBS polymer membrane, single VOC tests, and ceramic bilayer membrane for TCA and TCE transport reported that flux increased linearly with increasing feed concentration. Water flux stayed relatively constant over the range of concentration. $K_{\mathrm{ov}}$ increases with flow rate, proving the domination of boundary layer resistance in the overall transport of TCA across the membrane. Selectivity was found to increase with flow rate.

\section{Intensification of the Esterification Reaction Using Pervaporation}

Esterification is one of the most important chemical reactions in the chemical industry. Esters are derived from carboxylic acid by the replacement of hydrogen in the $\mathrm{COOH}$ group of acid by the hydrocarbon group of alcohol. Esterification reaction is a slow reaction and is reversible in nature. The reaction is carried out in the presence of the catalyst. Homogeneous catalysts, such as $\mathrm{H}_{2} \mathrm{SO}_{4}, \mathrm{HCl}$ [80], and p-toluenesulfonic acid [14], are frequently employed to esterification process. However, these catalysts have been found to attack membranes as well as the devices and are difficult to be separated from the products. As a result, there is an increasing effect on heterogeneous catalysts, such as ionexchange resin [81], zeolite [82], and solid super acid [83]. Ion-exchange resin has displayed comprehensive superiority in many situations [84]. Amberlyst 15 ion-exchange resin possesses distinct advantages including being environmentally benign, being nontoxic, being long-term chemically and physically stable [85], and being easily recyclable $[43,84,86]$ and has been successfully explored as a powerful catalyst for the esterification reaction.

Since the reaction is a reversible reaction and is equilibrium limited, the yield of ester is generally small. It is recommended that the ester be distilled off as soon as it is formed so that the reverse reaction does not happen. To improve the yield, it is customary to drive the position of the equilibrium to the ester side by either using excess of one of reactants (usually alcohol) or removal of the product of the reaction. However, there are challenges involved such that using excess of reactant would result in increased cost of the subsequent separation as the product stream is obtained in diluted form in the excess reactant. Subsequent removal of the product of the reaction via processes such as reactive distillation required that the difference in the volatility of product and reactants be sufficiently large. This is usually not the case in many processes and in addition formations of azeotropes were noted. The mismatching of the reaction and distillation temperature is an additional complication and in many cases the process performance and energy consumption in reactive distillation are the major cost factor in the manufacturing of esters.

\section{Comparison of Esterification with and without Pervaporation}

The integration of esterification reactor with a pervaporation pilot plant via hybrid reactor permits the selective permeation of the component (water) from the mixture. Hence the conversion of thermally limited esterification reaction is enhanced through controlled removal of one of the product species from the reaction mixture. Pervaporation is a rate controlled separation process and the separation efficiency is not limited by relative volatility. In pervaporation process, only water is permeated by membrane and accomplishes phase change. Hence, the energy required is comparatively lower. In addition to this, the temperature of operation of pervaporation setup matches with the temperature of reaction and hence could be advantageously used for enzymatic esterification due to temperature constraints normally imposed by enzyme stability. Different factors affect the pervaporation aided esterification reactor setup such as effect of initial molar ratios of the reactants, effect of catalyst concentration, effect of membrane area, and effect of temperature. Large membrane size could provide higher surface for the transfer of acid though the challenges of membrane rupture do surround the studies. An increase in temperature, catalyst concentration, and initial molar ratios of the reactants induces not only an acceleration of esterification but also acceleration in pervaporation.

The combination of pervaporation with the chemical reaction is very attractive system nowadays. The coupling of pervaporation separation process into conventional esterification processes with suitable membranes enhances the yield of the esters and conversion of acids [16, 44, 73]. Intensification of esterification of acetic acid and n-butyl alcohol using $\mathrm{Zr}\left(\mathrm{SO}_{4}\right)_{2} \cdot 4 \mathrm{H}_{2} \mathrm{O}$ using $\mathrm{PVA} /$ ceramic composite membrane was studied by Liu and Chen [87]. PV enhanced the conversion and it was higher for the PV-aided esterification than for the reaction without PV. Water content for the reaction without $\mathrm{PV}$ was higher than that for the $\mathrm{PV}$-aided reaction due to water removal by PV. Table 3 and Figures 7 and 8 list comparative study of esterification reaction system without and with incorporated with pervaporation separation process. It summarizes the results of pervaporation esterification integrated system in terms of conversion, when compared to a nonintegrated system.

\section{Effect of Operating Conditions on Esterification Coupled Pervaporation Process}

Operating parameters were classified in three groups [88]:

(1) Factors which influence directly the esterification kinetics: catalyst concentration and initial reactant molar ratio (alcohol/acid).

(2) Factors that influence directly pervaporation kinetics: ratio of membrane area to initial reaction volume $\left(A / V_{o}\right)$. 
TABLE 3: Comparison of results of esterification reaction with and without pervaporation.

\begin{tabular}{|c|c|c|c|c|}
\hline Esterification system & Catalyst/membrane & $\begin{array}{l}\text { Without } \\
\text { pervaporation }\end{array}$ & With pervaporation & Reference \\
\hline $\begin{array}{l}\text { Benzyl alcohol and } \\
\text { acetic acid }\end{array}$ & $\begin{array}{l}\text { p-Toluenesulfonic acid, GFT } \\
\text { membrane (GFT PERVAP 1005) }\end{array}$ & $\begin{array}{l}\text { Conversion of acetic } \\
\text { acid }=0.45\end{array}$ & $\begin{array}{l}\text { Conversion of acetic } \\
\text { acid }=0.6\end{array}$ & {$[44]$} \\
\hline Ethanol and acetic acid & $\mathrm{HCl}$, hydrophilic membrane & $\begin{array}{l}\text { Equilibrium } \\
\text { conversion }=0.6\end{array}$ & $\begin{array}{l}\text { Equilibrium } \\
\text { conversion }=0.82\end{array}$ & {$[128]$} \\
\hline Ethanol and lactic acid & Amberlyst 15, PERVAP 2201 & $\begin{array}{l}\text { Conversion of lactic } \\
\text { acid }=0.21\end{array}$ & $\begin{array}{l}\text { Conversion of lactic } \\
\text { acid }=0.88\end{array}$ & {$[16]$} \\
\hline Lactic acid and ethanol & $\begin{array}{l}\text { Amberlyst } 15 \text { ion exchange resin, } \\
\text { organic-inorganic hybrid membrane }\end{array}$ & $\begin{array}{l}\text { Yield of ethyl lactate }= \\
66 \%[\mathrm{wt}]\end{array}$ & $\begin{array}{l}\text { Yield of ethyl lactate }= \\
80 \%[\mathrm{wt}]\end{array}$ & {$[73]$} \\
\hline $\begin{array}{l}\text { Acetic acid and n-butyl } \\
\text { alcohol }\end{array}$ & $\begin{array}{l}\mathrm{Zr}\left[\mathrm{SO}_{4}\right]_{2} \cdot 4 \mathrm{H}_{2} \mathrm{O}, \mathrm{PVA} / \text { ceramic } \\
\text { composite membrane }\end{array}$ & $\begin{array}{l}\text { Conversion of } \\
\text { n-butanol }=0.65\end{array}$ & $\begin{array}{l}\text { Conversion of } \\
\text { n-butanol }=0.89\end{array}$ & {$[87]$} \\
\hline $\begin{array}{l}\text { Acrylic acid and } \\
\text { n-butanol }\end{array}$ & Amberlyst 131, PERVAP 2201 & $\begin{array}{l}\text { Conversion of acrylic } \\
\text { acid }=0.68\end{array}$ & $\begin{array}{l}\text { Conversion of acrylic } \\
\text { acid }=0.96\end{array}$ & {$[129]$} \\
\hline Oleic acid and ethanol & $\begin{array}{l}\text { Amberlyst } 15 \text {, hydrophilic } \\
\text { poly[vinyl alcohol] }\end{array}$ & $\begin{array}{l}\text { Yield of ethyl oleate }= \\
23 \%\end{array}$ & $\begin{array}{l}\text { Yield of ethyl oleate }= \\
50 \%\end{array}$ & {$[130]$} \\
\hline $\begin{array}{l}\text { Acetic acid with } \\
\text { isopropanol }\end{array}$ & $\begin{array}{l}\text { Amberlyst 15, PVA membrane, } \\
\text { PERVAP } 2201\end{array}$ & $\begin{array}{l}\text { Mole fraction of } \\
\text { isopropyl acetate }=0.3\end{array}$ & $\begin{array}{l}\text { Mole fraction of } \\
\text { isopropyl acetate }= \\
0.61\end{array}$ & {$[38]$} \\
\hline Lactic acid with ethanol & $\begin{array}{l}\text { Amberlyst XN-1010, water selective } \\
\text { membrane }\end{array}$ & $\begin{array}{l}\text { Conversion of lactic } \\
\text { acid }=0.5\end{array}$ & $\begin{array}{l}\text { Conversion of lactic } \\
\text { acid }=0.82\end{array}$ & {$[131]$} \\
\hline Acetic acid and ethanol & $\begin{array}{l}\text { Sulfuric acid, polymeric/ceramic } \\
\text { composite membrane }\end{array}$ & $\begin{array}{l}\text { Conversion of acetic } \\
\text { acid }=0.72\end{array}$ & $\begin{array}{l}\text { Conversion of acetic } \\
\text { acid }=0.81\end{array}$ & {$[100]$} \\
\hline Lactic acid with ethanol & Amberlyst XN-1010, GFT-1005 & $\begin{array}{l}\text { Conversion of lactic } \\
\text { acid }=0.522\end{array}$ & $\begin{array}{l}\text { Conversion of lactic } \\
\text { acid }=0.712\end{array}$ & {$[19]$} \\
\hline $\begin{array}{l}\text { Lactic acid with } \\
\text { isopropanol }\end{array}$ & $\begin{array}{l}\text { Sulfuric acid, PVA-PES composite } \\
\text { membrane }\end{array}$ & $\begin{array}{l}\text { Conversion of lactic } \\
\text { acid }=0.51\end{array}$ & $\begin{array}{l}\text { Conversion of lactic } \\
\text { acid }=0.86\end{array}$ & {$[132]$} \\
\hline $\begin{array}{l}\text { Lactic acid with } \\
\text { n-butanol }\end{array}$ & $\begin{array}{l}\text { Sulfuric acid, PVA-PES composite } \\
\text { membrane }\end{array}$ & $\begin{array}{l}\text { Conversion of lactic } \\
\text { acid }=0.66\end{array}$ & $\begin{array}{l}\text { Conversion of lactic } \\
\text { acid }=0.88\end{array}$ & {$[133]$} \\
\hline Acetic acid and ethanol & $\begin{array}{l}\text { Dowex50, PVA-PVP incorporating } \\
\text { PMA mixed matrix membrane }\end{array}$ & $\begin{array}{l}\text { Conversion of acetic } \\
\text { acid }=0.264\end{array}$ & $\begin{array}{l}\text { Conversion of acetic } \\
\text { acid }=0.6065\end{array}$ & {$[134]$} \\
\hline \multirow{2}{*}{ Acetic acid with ethanol } & $\begin{array}{l}\text { Amberlyst } 15 \text {, polydimethylsiloxane } \\
\text { membrane }\end{array}$ & $\begin{array}{l}\text { Conversion of acetic } \\
\text { acid }=0.57\end{array}$ & $\begin{array}{l}\text { Conversion of acetic } \\
\text { acid }=0.65\end{array}$ & \multirow{2}{*}[42]{} \\
\hline & $\begin{array}{l}\text { Sulfuric acid, polydimethylsiloxane } \\
\text { membrane }\end{array}$ & $\begin{array}{l}\text { Conversion of acetic } \\
\text { acid }=0.63\end{array}$ & $\begin{array}{l}\text { Conversion of acetic } \\
\text { acid }=0.71\end{array}$ & \\
\hline
\end{tabular}

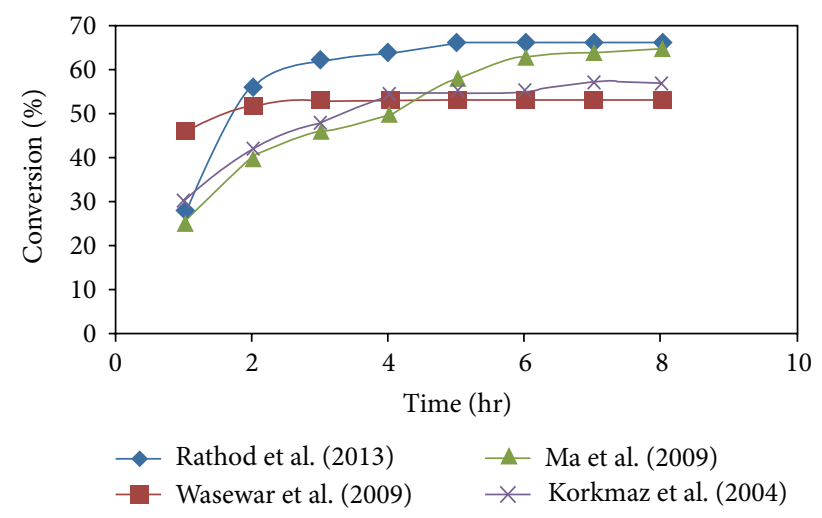

FIgURE 7: Different trends of conversion of acid with time for esterification without pervaporation system.

(3) Factors that influence simultaneously the esterification and pervaporation kinetics: temperature.

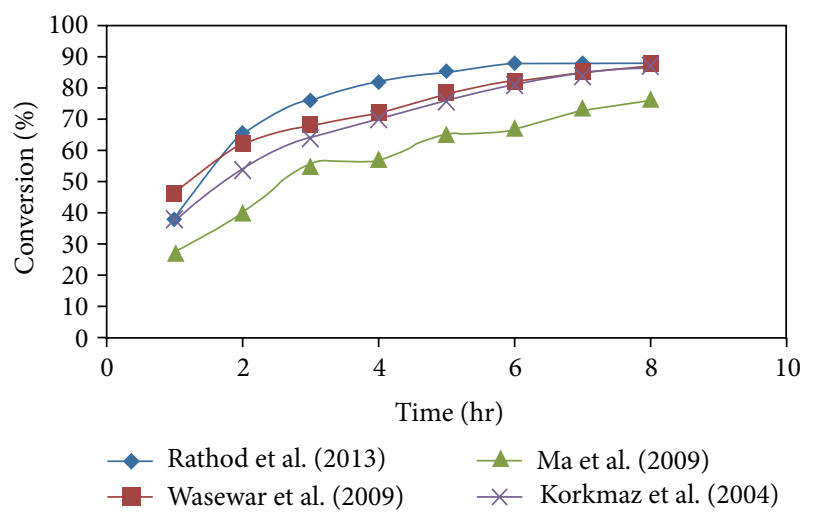

FIGURE 8: Different trends of conversion of acid with time for esterification with pervaporation system.

7.1. Effect of Initial Reactant Ratio. Delgado et al. [16] studied effect of ethanol: lactic acid initial feed molar ratio $(R)$ over 
a range of $1: 1$ to $3: 1$; catalyst (Amberlyst 15) loading, 2\%; ratio membrane (PERVAP 2201) area to initial volume of reaction, $S / V_{o}=23 \mathrm{~m}^{-1}$; and reaction and pervaporation temperature, $348.15 \mathrm{~K}$. It was found that at the beginning of the process the higher the initial reactant molar ratio, the higher the reaction rate. However, as the reaction proceeds, it was found that higher ester formation was obtained when working in stoichiometric proportion. This may be due to the dilution effect of ethanol. In simple esterification reactions, higher equilibrium conversions were obtained by increasing the initial reactant molar ratio, but the limited reactant will never react completely. In esterification-pervaporation reactors a complete conversion of one reactant is obtainable when the other reactant is in excess, no matter how small the excess is. Conversion in this kind of integrated process can go beyond the equilibrium conversion, which is the maximum conversion reached in a conventional reactor.

In pervaporation aided esterification of acetic acid and n-butyl alcohol using catalyst, p-toluenesulfonic acid and solid super acid, and membrane, phosphatic poly(vinyl alcohol)/poly acrylonitrile (PPVA/PAN) composite membrane, Xuehui and Lefu [90] found that higher ester formation occurs at higher $R$ for fixed time (where $R$ is ratio of initial molar quantity of alcohol to acid). Maxima in water concentration also obtained at lower times when higher $R$ is used. Liu et al. [89] reported the result of esterification of acetic acid + n-butyl alcohol $+\mathrm{Zr}\left(\mathrm{SO}_{4}\right)_{2} \cdot 4 \mathrm{H}_{2} \mathrm{O}+\mathrm{PVA} /$ ceramic composite membrane, in the form of dimensionless parameter, $F$, that stands for the interaction between water removal and water production during the coupling process. Conversion was increased and water production rate decreases with $R_{o}$ increasing. Maximum in water content in the mixture had higher amplitude at a lower $R_{o}$.

Ma et al. [73] reported that the yield of ethyl lactate using Amberlyst 15 ion exchange resin did not remarkably increase with the initial molar ratio of ethanol to lactic acid from 2 to 4. $R_{o}$ played a part in reaction rate but exerted no effect on kinetics of PV. Water production rate is decreased with the increase of $R_{o}$ and caused the maximum amplitude in water content lower at a higher $R_{o}$.

7.2. Effect of Catalyst Concentration. In the esterification of benzyl alcohol and acetic acid using p-toluenesulfonic acid and employing commercial GFT membrane (GFT PERVAP 1005), Domingues et al. [44] found that increase in the amount of catalyst leads to an increase in the reaction rate; however beyond $4.1 \mathrm{~mol} / \mathrm{m}^{3}$, there is no significant increase. Liu et al. [89] (system: acetic acid + n-butyl alcohol + $\mathrm{Zr}\left(\mathrm{SO}_{4}\right)_{2} \cdot 4 \mathrm{H}_{2} \mathrm{O}+\mathrm{PVA} /$ ceramic composite membrane) found that water production rate was proportional to and increased with the increase of catalyst concentration. When the catalyst concentration was increased, the maximum in water content in the mixture was increased and shifted to shorter time and the final water content decreased. $\mathrm{Ma}$ et al. [73] varied Amberlyst 15 from $0.5 \mathrm{wt} \%$ to $3.0 \mathrm{wt} \%$ in esterification of lactic acid + ethanol in pervaporation studied in organic-inorganic hybrid membrane prepared by in site hydrolysis and condensation of tetraethoxysilane with chitosan aqueous solution. Yield of ethyl lactate was improved with the increase of catalyst loading. The reason for this is increasing catalyst active sites and decreasing of reaction activation energy which could obviously accelerate reaction rate. The water contents in the reactor had higher maximum amplitude for a higher catalyst concentration during the reaction. Delgado et al. [16] studied effect of catalyst (Amberlyst 15) concentration (2, 3.5, and $5.5 \mathrm{wt} \%$ of total initial solution) in esterification of ethanol + lactic using PERVAP 2201. Increase in the amount of catalyst leads to an increase in the reaction rate. In the studies on dilute acid the effect is not higher due to the high initial amount of water in the reactor.

7.3. Effect of Membrane Area to Initial Reaction Volume Ratio. Delgado et al. [16] varied the membrane area to initial reaction volume ratio for $12-46 \mathrm{~m}^{-1}$ in the esterification of ethanol and lactic acid using Amberlyst 15 and PERVAP 2201. It was found that the higher the value of this ratio, the higher the ethyl lactate concentration in the reactor; therefore higher conversions are reached. This result is obvious since water concentration in the reactor will decrease faster when the membrane area per unit of reaction volume is larger. Domingues et al. [44] found that in the esterification studies on benzyl alcohol and acetic acid using p-toluenesulfonic acid as catalyst and GFT PERVAP 1005 membrane to obtain $60 \%$ conversion of AA increase in membrane surface area $(S)$ leads to less operating time to reach the conversion level. In addition the 100 percent conversion of alcohol was achieved.

To measure the capacity of membrane unit, membrane parameter $\omega$ (characterizing membrane permeability) and operating parameters $S$ and $V_{o}$ are combined as a single variable, $\omega S / V$ (permeability $*$ surface area/volume of reaction mixture) [60]. It was found that conversion of the membrane reactor can go beyond the equilibrium conversion. Gap between the two limits, that is, $\omega S / V$ varies from 0 to infinity, becomes larger as the reaction time increases, indicating that the reaction is increasingly facilitated by membrane pervaporation. The higher the value of $\omega S / V$, the higher the conversion. When membrane is used to enhance the reaction, water concentration $\left(C_{w} / C_{o}\left\{C_{w}\right.\right.$ is water concentration and $C_{o}$ is the water concentration that would be obtained at complete conversion\}) undergoes a maximum as reaction proceeds in time. The larger the value of $\omega S / V$, the shorter the time required for water to reach maximum concentration and the smaller the magnitude of the maximum water concentration. As reaction proceeds, reaction rate decreases. Such a decrease in reaction rate is, however, slowed down by the use of a membrane because selective removal of water further concentrates the reactants. Despite the fact that pervaporation can shift the equilibrium toward the ester side and go beyond equilibrium conversion, it cannot drive the reaction to completion, that is, $X=1$, in a finite time scale, no matter how large the value of $\omega S / V$ is. When one of the reactant species is used in excess, a complete conversion of the other is achievable.

The result was explained in the way that the concentration of water in the reactor will be reduced more rapidly when the membrane is more permeable and/or when the membrane 
area per unit reaction volume is larger, so higher is the conversion. During the early period of reaction, the rate of chemical reaction is high, whereas water concentration is low and so is the rate of water removal from the reactor. Consequently, water concentration gradually increases until it reaches maximum when its formation rate and removal rate become equal. Thereafter the water removal is faster than formation, resulting in depletion of water in the reactor.

Liu et al. [89] (system: acetic acid + n-butyl alcohol + $\mathrm{Zr}\left(\mathrm{SO}_{4}\right)_{2} \cdot 4 \mathrm{H}_{2} \mathrm{O}+\mathrm{PVA} /$ ceramic composite membrane) stated that rate of water removal was reduced with the decrease of $S / V$. Further liquid had higher amplitude at a lower $S / V$. Ma et al. [73] (system: lactic acid + ethanol + Amberlyst $15+$ organic-inorganic hybrid membrane) found that $S / V$ exerted no influence on reactive kinetics but caused the variation of the water extraction rate. Water production rate is decreased with the increase of $S / V$.

7.4. Effect of Temperature of Reaction and Pervaporation. Delgado et al. [16] in the esterification of ethanol and lactic acid using Amberlyst 15 and PERVAP 2201 found that water content in the reaction medium decreased rapidly when membrane permeation flux increased as a consequence of an increase in pervaporation temperature $(338.15,348.15$, and $358.15 \mathrm{~K})$. As a result, the esterification rate increases. Xuehui and Lefu [90] (system: acetic acid + n-butyl alcohol + p-toluenesulfonic acid and solid super acid + PPVA/PAN composite membrane) reported that higher ester is formed at higher temperature for fixed time. Maxima in water concentration also obtained at lower times when higher temperature is used.

Liu et al. [89] (system: acetic acid + n-butyl alcohol + $\mathrm{Zr}\left(\mathrm{SO}_{4}\right)_{2} \cdot 4 \mathrm{H}_{2} \mathrm{O}+\mathrm{PVA} /$ ceramic composite membrane) found that dimensionless parameter, $F$, that stands for the interaction between water removal and water increases with increasing temperature indicating that the acceleration of the rate of water extraction is faster than that of water production rate. This is due to the reason that both the water production rate and permeability coefficient are higher at a higher temperature. Maximum in water concentration was increased with temperature but shifted to a shorter time due to the higher water production rate. Before the water content went through its maximum value, the rate of water production was larger than that of water removal; after water content attained the maximum value, the rate of water production was less than that of water removal.

$\mathrm{Ma}$ et al. [73] studied the effect of temperature from $50^{\circ} \mathrm{C}$ to $80^{\circ} \mathrm{C}$ in the esterification of lactic acid + ethanol using Amberlyst 15 ion exchange resin and organic-inorganic hybrid membrane. Esterification of lactic acid and ethanol was an endothermic reaction (based on Arrhenius plot); accordingly, the yield of ethyl lactate increased with increasing reaction temperature in pervaporation assisted esterification. Liu and Chen [87] (system: acetic acid + n-butyl alcohol $+\mathrm{Zr}\left(\mathrm{SO}_{4}\right)_{2} \cdot 4 \mathrm{H}_{2} \mathrm{O}+\mathrm{PVA} /$ ceramic composite membrane) found that reaction rate constants for the esterification are a function of process temperature and were increased with the increase of the temperature $\left(70-90^{\circ} \mathrm{C}\right)$. The accelerating of the reaction rate constant with the increase of the temperature for the forward reaction was faster than the backward process. So water production rate was higher in a higher temperature than in a lower temperature. Meanwhile, the permeation parameter for water is also varied with the temperature and was increased with the increase of the temperature. As a result, water permeation flux was increased with the increase of the process temperature. Water concentration had a higher maximum value for a higher process temperature. This may be explained by the fact that the acceleration for water production rate had a higher value at a higher temperature, so water content increased faster during the earlier reaction stage due to a slower backward reaction rate, while it decreased faster later due to a higher backward reaction rate.

Grob and Heintz [91] studied isotherms of aromatic compounds in organophilic polymer membranes (polyetherpolyamide block-copolymer (PEBA)), used in pervaporation, and found that sorption of phenol, aniline, 2-chlorophenol, 4nitrophenol, 2,4-dinitrophenol, 4, ${ }^{\prime}$-isopropylidenediphenol (bisphenol A), and pyridine decreases with temperature. Sorption coefficients are obtained as slopes of the straight lines. The number of the free hydroxyl groups plays a certain role for the affinity of the aromatic compounds for the membrane material PEBA. The sorption process of transferring aromatics from aqueous solution to the membrane is exothermic. Values of calculated sorption enthalpies $\Delta h_{\text {infinity }}$ range between -25 and $-12 \mathrm{~kJ} / \mathrm{mol}$. The sorption of both aniline and phenol in the membrane material was not affected by the presence of the second aromatic compound. The system phenol/bisphenol A shows a certain synergistic solubility effect. The solubility of phenol is enhanced by the presence of bisphenol $\mathrm{A}$, but the phenol has no influence on the solubility of bisphenol A. Burshe et al. [71] studied dehydration of glycerine-water mixtures by pervaporation using membranes such as Nafion (NA), cellulose triacetate (CA), polyimide, carboxylated polyvinyl chloride (CPVC), and polyethersulfone (PES). Temperature was varied from 30 to $70^{\circ} \mathrm{C}$. It was found that increased feed temperature decreased the sorption of water and heat of sorption $\left(\Delta H_{s}\right)$ is negative.

\subsection{Other Factors}

7.5.1. Effect of Downstream Pressure on Various Terms. Generally downstream pressure is less than $1 \mathrm{~mm} \mathrm{Hg}$. If downstream pressure increases, at membrane permeant interface, desorption slows down; thus downstream pressure becomes the rate controlling. Increase in pressure increases the activity of both permeances dissolved in the downstream layer of the working membrane. If pressure increases and exceeds the saturated vapor pressure of permeance, selectivity falls. At low downstream pressure, desorption is rapid; thus diffusion becomes the rate controlling. Beyond the transition pressure, desorption slows down and progressively governs the selectivity of pervaporation transport. In this regime, selectivity is determined by the relative volatilities of the feed components. If the more rapid permeating species is also the more volatile, selectivity increases as the downstream pressure is raised. In the opposite case a steep decrease in 
selectivity is observed. For ideal gas mixtures with permeance containing no significant amount of noncondensable gas, the permeant composition $\left(X_{A}^{\prime}\right.$, mole fraction) depends on the downstream pressure $(P)$ :

$$
X_{A}^{\prime}=\frac{P_{A} P_{B}}{P_{B}^{*}-P_{A}^{*}} \frac{1}{P}-\frac{P_{A}}{P_{B}^{*}-P_{A}^{*}},
$$

where $A$ and $B$ are the fast and slow permeances.

Derivation gives

$$
\frac{d X_{A}}{d P}=\frac{P_{A} P_{B}}{P_{B}^{*}-P_{A}^{*}} \times \frac{1}{P^{2}} .
$$

If $A$ is less volatile, $P_{A}^{*}-P_{B}^{*}<0$, and selectivity decreases as $P$ increases.

Burshe et al. [71] in the dehydration studies on glycerinewater mixture using various membranes found the effect of downstream pressure on the dehydration. Pressure was varied from 1 to $20 \mathrm{~mm} \mathrm{Hg}$. It was found that higher the downstream pressure lower in water flux. Selectivity is not affected by downstream pressure change. It is recommended that it is better to use $20 \mathrm{~mm} \mathrm{Hg}$ downstream pressures as this reduces the load on the refrigeration unit supplying the cooling medium for condensing the water issuing from the equipment.

7.5.2. Effect of Molecule Size on the Permeability of Different Compounds. Song et al. [76] studied the permeation of different ester compounds (ethyl acetate, EA; ethyl propionate, EP; ethyl butyrate, EB) through surface-modified alumina membrane $\left(\mathrm{Al}_{2} \mathrm{O}_{3}\right)$. Ester (EA, EP, and $\left.\mathrm{EB}\right)$ concentrations in permeance increased almost linearly with increasing ester concentrations in the feed. The ester concentration in permeance increased in the order of EB $>$ EP $>$ EA as well as ester flux, even though molecular weight and molar volume of EB are greater than EP and EA. This may be attributed to the lowest solubility of EB in water, since the low solubility relates to the high hydrophobicity. Due to the lowest solubility, EB has highest affinity to the hydrophobic surface of the membrane. This is as would be expected, since organic species have a stronger affinity to the organophilic membrane than water-soluble solutes. Although the concentration of esters (EA, EP, and EB) was only $0.15-0.60 \mathrm{wt} \%$ in the feed, EA, $\mathrm{EP}$, and $\mathrm{EB}$ in permeance were concentrated up to 9.13$32.26,13.79-37.0$, and $15.33-42.57$ wt $\%$, respectively. Phase separation occurred in permeant stream because the ester concentration in permeance was much above the saturation limit.

The difference in the flux and permeance of different component in a particular membrane is explained in terms of difference in affinity between the component and the membrane for the different components. A simple approach to describing the affinity between materials is the solubility parameter. Guo et al. [72] in the studies of dehydration of butanol mixtures found that the solubility parameters $\delta \mathrm{sp}(\mathrm{MPa} 1 / 2)$ of PVA (the selective layer of membrane) and water are 39.1 and 47.9 , respectively. The difference between solubility parameters for each pair of butanol/membrane is in the order of 1-butanol/membrane $(16)<$ isobutanol/membrane $(16.4)<$ 2-butanol/membrane (17) < tert-butanol/membrane (17.4). The solubility parameter theory proposes that the materials will have strong interaction when their respective solubility parameters are close to each other. Therefore, based on this theory, the affinity between the butanol and the membrane is in the order of 1-butanol > isobutanol $>2$-butanol $>$ tertbutanol. Accordingly, the butanol fluxes present the same order, so do the butanol permeances.

Hasanoglu et al. [64] studied hydrolysis reaction of ethyl acetate (ethyl acetate (EAc), water, ethanol $(\mathrm{EOH})$, and acetic acid (AsAc)) using polydimethylsiloxane (PDMS). PDMS membrane permeates EAc much more than the other components. This is not unexpected because the solubility parameter of PDMS is closer to ethyl acetate than the other components $\left(\delta_{\text {PDMS }}=8.1\left(\mathrm{cal} / \mathrm{cm}^{3}\right)^{0.5}\right)$ [92]. Thus, PDMS is more selective to ethyl acetate than other components. The solubility parameter is a measure of the affinity between polymer and penetrant and can give qualitative information about interaction between polymer and penetrant. As the affinity between permeant and polymer increases the amount of liquid inside the polymer increases, and consequently the flux through the membrane increases [93].

\section{Conclusion}

Membranes both hydrophilic and hydrophobic are widely used in industries for both product recovery and waste treatment. Nowadays it is widely used in industries for dehydrating solvents such as ethanol and isopropanol. As pervaporation is independent of vapor/liquid equilibria, it can preferentially remove water from a stream irrespective of the other components present. Therefore it can be considered as a substitute where distillation is difficult or costly. Moreover, pervaporation can be used progressively to improve reactor performance, by either purifying feeds or separating reaction products. Since pervaporation is a membrane process, these separations can be combined with the reaction step, resulting in substantial improvements in reaction efficiencies, yields, and process economics. In this regard lots of scope exists for separation of esterification product or the byproduct. Research is going on to develop new and better membranes, that is, with higher fluxes, better selectivity, and broader chemical resistance which will expand the areas where pervaporation-esterification hybrid is feasible.

\section{Nomenclature}

$k_{l}$ : $\quad$ Boundary layer mass transfer coefficient on the liquid side

$x_{i, l}$ : Organic concentration at the liquid-membrane interface

$K_{i}$ : Membrane mass transfer coefficient

$t: \quad$ Membrane thickness

$x_{f}, x_{g}$ : Concentration of component in feed and permeance

$J_{i}$ : $\quad$ Flux of $i$ across the membrane 


\begin{tabular}{|c|c|c|c|}
\hline$Q_{\mathrm{ov}, i}:$ & $\begin{array}{l}\text { The overall mass transfer coefficient } \\
\text { of } i \text { in terms of vapor pressure }\end{array}$ & $w_{i}:$ & $\begin{array}{l}\text { Weight fraction of the compound } i \\
\text { in the feed }\left(w_{i}^{\text {feed }}\right) \text { and in the }\end{array}$ \\
\hline$A:$ & Membrane area & & permeance $\left(w_{i}^{\text {permeate }}\right)$ \\
\hline$p_{l, i}, p_{g, i}:$ & & $p^{p}:$ & Permeant pressure \\
\hline & $\begin{array}{l}\text { liquid side and in the permeance (or } \\
\text { gas) side, respectively }\end{array}$ & & Ideal membrane selectivity \\
\hline$K_{\mathrm{ov}, i}:$ & $\begin{array}{l}\text { Overall mass transfer coefficient of } i \\
\text { in terms of liquid concentration }\end{array}$ & $C_{p \text { water }}, C_{f \text { water }}:$ & $\begin{array}{l}\text { Water concentrations in the } \\
\text { permeance and feed, respectively }\end{array}$ \\
\hline & Concentration of $i$ in the liquid & $J_{p}:$ & Permeation flux $\left(\mathrm{kg} / \mathrm{m}^{2} \mathrm{~h}\right)$ \\
\hline$C_{g, i_{l, i}^{*}}^{*}:$ & Concentration of $i$ in the liquid & $S_{o}:$ & Temperature-independent \\
\hline$p_{l, i}:$ & $\begin{array}{l}\text { Partial vapor pressure of } i \text { in the } \\
\text { liquid side }\end{array}$ & $\Delta H_{s}:$ & $\begin{array}{l}\text { constant } \\
\text { Heat of solution }\end{array}$ \\
\hline$p_{g, i}:$ & $\begin{array}{l}\text { Partial vapor pressure of } i \text { in the gas } \\
\text { side }\end{array}$ & $D_{o}:$ & $\begin{array}{l}\text { Temperature-independent } \\
\text { constant in (33) }\end{array}$ \\
\hline$C_{g, i}:$ & Concentration in the gas side & $E_{d}:$ & $\begin{array}{l}\text { Activation energy for diffusion or } \\
\text { it is a preexponential factor }\end{array}$ \\
\hline$\gamma_{i}:$ & $\begin{array}{l}\text { Activity coefficient of } i \text { in the liquid } \\
\text { side }\end{array}$ & $P_{w}^{o}, \gamma_{w}:$ & The saturated vapor pressure and \\
\hline$p_{i}^{0}:$ & $\begin{array}{l}\text { Saturation vapor pressure of pure } i \\
\text { at the liquid temperature }\end{array}$ & & $\begin{array}{l}\text { the activity coefficient of water, } \\
\text { respectively }\end{array}$ \\
\hline$\rho_{l}:$ & Molar density of the liquid & $x_{w}:$ & Mole fraction of water in an \\
\hline$p_{T}:$ & Total pressure in the gas side & & ethanol/water mixture \\
\hline$\rho_{g}:$ & Molar density of the gas & $\phi:$ & Volume fraction of penetrant \\
\hline $\begin{array}{l}K_{\text {ov, }} \\
f_{i}:\end{array}$ & & $\gamma:$ & $\begin{array}{l}\text { Exponential constant (plasticizing } \\
\text { constant, indicating the }\end{array}$ \\
\hline $\begin{array}{l}J_{i}: \\
P_{i}:\end{array}$ & $\begin{array}{l}\text { Fugacity of component } \imath \\
\text { Permeability coefficient }\end{array}$ & & plasticizing action of the penetrant \\
\hline$l:$ & Thickness of the active layer of the & & on segmental motion) \\
\hline & $\begin{array}{l}\text { membrane } \\
\text { Solubility coefficient of the in the }\end{array}$ & $D_{o}$ & $\begin{array}{l}\text { Diffusion concentration at zero } \\
\text { concentration in }(41)\end{array}$ \\
\hline & membrane & $a_{i}:$ & Activity of penetrant inside the \\
\hline$D_{i}:$ & $\begin{array}{l}\text { Diffusion coefficient of the in the } \\
\text { membrane }\end{array}$ & $V_{o}:$ & $\begin{array}{l}\text { polymer } \\
\text { Volume occupied by molecules at }\end{array}$ \\
\hline$\gamma p^{0} / \rho_{l}$ & $\begin{array}{l}\text { Conversion factor from a } \\
\text { concentration driving force to a } \\
\text { partial vapor pressure driving force }\end{array}$ & $D_{T}:$ & $\begin{array}{l}0 \mathrm{~K} \\
\text { Thermodynamic diffusion } \\
\text { coefficient }\end{array}$ \\
\hline$Q_{\mathrm{ov}}:$ & $\begin{array}{l}\text { Overall mass transfer coefficient (in } \\
\text { terms of vapor pressure driving }\end{array}$ & $\chi:$ & $\begin{array}{l}\text { Interaction parameter is molar } \\
\text { volume }\end{array}$ \\
\hline & force) & $d:$ & Volume fraction of penetrant \\
\hline$K_{\mathrm{ov}}:$ & $\begin{array}{l}\text { Overall mass transfer coefficient (in } \\
\text { terms of concentration driving } \\
\text { force) }\end{array}$ & $J_{w}\left(T^{o}, P^{o}\right):$ & $\begin{array}{l}\text { Water flux measured at a feed side } \\
\text { temperature of } T^{o} \text { and permeant } \\
\text { side pressure of } P^{o} \text {. }\end{array}$ \\
\hline
\end{tabular}

\section{Conflict of Interests}

The authors declare that there is no conflict of interests regarding the publication of this paper.

\section{Acknowledgment}

This work was supported by the DST, Ministry of Science and Technology, New Delhi, India (SB/FTP/ETA-97/2012).

\section{References}

[1] J. G. Crespo and C. Brazinha, "Fundamentals of pervaporation," in Pervaporation, Vapour Permeation and Membrane Distillation, A. Basile, A. Figoli, and M. Khayet, Eds., chapter 1, Woodhead Publishing, Elsevier, Amsterdam, The Netherlands, 1st edition, 2015. 
[2] B. V. Bruggen and P. Luis, "Pervaporation," in Progress in Filtration and Separation, R. J. Wakeman, Ed., chapter 4, Elsevier Scientific, 1979, University of California, 2015.

[3] L. Aouinti, D. Roizard, and M. Belbachir, "PVC-activated carbon based matrices: a promising combination for pervaporation membranes useful for aromatic-alkane separations," Separation and Purification Technology, vol. 147, pp. 51-61, 2015.

[4] C. P. Ribeiro, B. D. Freeman, D. S. Kalika, and S. Kalakkunnath, "Aromatic polyimide and polybenzoxazole membranes for the fractionation of aromatic/aliphatic hydrocarbons by pervaporation," Journal of Membrane Science, vol. 390-391, pp. 182-193, 2012.

[5] Z. Li, B. Zhang, L. Qu, J. Ren, and Y. Li, "A novel atmospheric dielectric barrier discharge (DBD) plasma graft-filling technique to fabricate the composite membranes for pervaporation of aromatic/aliphatic hydrocarbons," Journal of Membrane Science, vol. 371, no. 1-2, pp. 163-170, 2011.

[6] J. Kujawa, S. Cerneaux, and W. Kujawski, "Highly hydrophobic ceramic membranes applied to the removal of volatile organic compounds in pervaporation," Chemical Engineering Journal, vol. 260, pp. 43-54, 2015.

[7] A. A. Ghoreyshi, H. Sadeghifar, and F. Entezarion, "Efficiency assessment of air stripping packed towers for removal of VOCs (volatile organic compounds) from industrial and drinking waters," Energy, vol. 73, pp. 838-843, 2014.

[8] S.-K. Mah, S.-P. Chai, and T. Y. Wu, "Dehydration of glycerin solution using pervaporation. HybSi and polydimethylsiloxane membranes," Journal of Membrane Science, vol. 450, pp. 440446, 2014.

[9] P. Delgado, M. T. Sanz, and S. Beltrán, "Pervaporation of the quaternary mixture present during the esterification of lactic acid with ethanol," Journal of Membrane Science, vol. 332, no. 1-2, pp. 113-120, 2009.

[10] M.-H. Zhu, I. Kumakiri, K. Tanaka, and H. Kita, "Dehydration of acetic acid and esterification product by acid-stable ZSM-5 membrane," Microporous and Mesoporous Materials, vol. 181, pp. 47-53, 2013.

[11] W. Zhang, Z. Yu, Q. Qian, Z. Zhang, and X. Wang, "Improving the pervaporation performance of the glutaraldehyde crosslinked chitosan membrane by simultaneously changing its surface and bulk structure," Journal of Membrane Science, vol. 348, no. 1-2, pp. 213-223, 2010.

[12] C. Zhao, H. Wu, X. Li et al., "High performance composite membranes with a polycarbophil calcium transition layer for pervaporation dehydration of ethanol," Journal of Membrane Science, vol. 429, pp. 409-417, 2013.

[13] C. S. M. Pereira, V. M. T. M. Silva, S. P. Pinho, and A. E. Rodrigues, "Batch and continuous studies for ethyl lactate synthesis in a pervaporation membrane reactor," Journal of Membrane Science, vol. 361, no. 1-2, pp. 43-55, 2010.

[14] J. J. Jafar, P. M. Budd, and R. Hughes, "Enhancement of esterification reaction yield using zeolite A vapour permeation membrane," Journal of Membrane Science, vol. 199, no. 1, pp.117123, 2002.

[15] N. Agoudjil, S. Kermadi, and A. Larbot, "Synthesis of inorganic membrane by sol-gel process," Desalination, vol. 223, no. 1-3, pp. 417-424, 2008.

[16] P. Delgado, M. T. Sanz, S. Beltrán, and L. A. Núñez, "Ethyl lactate production via esterification of lactic acid with ethanol combined with pervaporation," Chemical Engineering Journal, vol. 165, no. 2, pp. 693-700, 2010.
[17] S. Assabumrungrat, J. Phongpatthanapanich, P. Praserthdam, T. Tagawa, and S. Goto, "Theoretical study on the synthesis of methyl acetate from methanol and acetic acid in pervaporation membrane reactors: effect of continuous-flow modes," Chemical Engineering Journal, vol. 95, no. 1, pp. 57-65, 2003.

[18] R. Krupiczka and Z. Koszorz, "Activity-based model of the hybrid process of an esterification reaction coupled with pervaporation," Separation and Purification Technology, vol. 16, no. 1, pp. 55-59, 1999.

[19] D. J. Benedict, S. J. Parulekar, and S.-P. Tsai, "Pervaporationassisted esterification of lactic and succinic acids with downstream ester recovery," Journal of Membrane Science, vol. 281, no. 1-2, pp. 435-445, 2006.

[20] Y. Zhu and H. F. Chen, "Pervaporation separation and pervaporation-esterification coupling using crosslinked PVA composite catalytic membranes on porous ceramic plate," Journal of Membrane Science, vol. 138, no. 1, pp. 123-134, 1998.

[21] T. A. Peters, N. E. Benes, and J. T. F. Keurentjes, "Preparation of Amberlyst-coated pervaporation membranes and their application in the esterification of acetic acid and butanol," Applied Catalysis A: General, vol. 317, no. 1, pp. 113-119, 2007.

[22] B. Sarkar, S. Sridhar, K. Saravanan, and V. Kale, "Preparation of fatty acid methyl ester through temperature gradient driven pervaporation process," Chemical Engineering Journal, vol. 162, no. 2, pp. 609-615, 2010.

[23] S.-M. Ahn, J.-W. Ha, J.-H. Kim, Y.-T. Lee, and S.-B. Lee, "Pervaporation of fluoroethanol/water and methacrylic acid/water mixtures through PVA composite membranes," Journal of Membrane Science, vol. 247, no. 1-2, pp. 51-57, 2005.

[24] J. M. L. Neel, Q. T. Nguyen, and H. Bruschke, "Composite membrane for separating water from fluids containing organic components by means of pervaporation," US Patent 5 334,314, 1994.

[25] P. M. Budd, N. M. P. S. Ricardo, J. J. Jafar, B. Stephenson, and R. Hughes, "Zeolite/polyelectrolyte multilayer pervaporation membranes for enhanced reaction yield," Industrial and Engineering Chemistry Research, vol. 43, no. 8, pp. 1863-1867, 2004.

[26] S. G. Adoor, L. S. Manjeshwar, S. D. Bhat, and T. M. Aminabhavi, "Aluminum-rich zeolite beta incorporated sodium alginate mixed matrix membranes for pervaporation dehydration and esterification of ethanol and acetic acid," Journal of Membrane Science, vol. 318, no. 1-2, pp. 233-246, 2008.

[27] L. M. Vane, "A review of pervaporation for product recovery from biomass fermentation processes," Journal of Chemical Technology and Biotechnology, vol. 80, no. 6, pp. 603-629, 2005.

[28] Y. Mori and T. Inaba, "Ethanol production from starch in a pervaporation membrane bioreactor using Clostridium thermohydrosulfuricum," Biotechnology and Bioengineering, vol. 36, no. 8, pp. 849-853, 1990.

[29] M. She and S.-T. Hwang, "Concentration of dilute flavor compounds by pervaporation: permeate pressure effect and boundary layer resistance modeling," Journal of Membrane Science, vol. 236, no. 1-2, pp. 193-202, 2004.

[30] N. Qureshi, M. M. Meagher, J. Huang, and R. W. Hutkins, "Acetone butanol ethanol (ABE) recovery by pervaporation using silicalite-silicone composite membrane from fed-batch reactor of Clostridium acetobutylicum," Journal of Membrane Science, vol. 187, no. 1-2, pp. 93-102, 2001.

[31] H. Matsuda, H. Yanagishita, H. Negishi et al., "Improvement of ethanol selectivity of silicalite membrane in pervaporation by silicone rubber coating," Journal of Membrane Science, vol. 210, no. 2, pp. 433-437, 2002. 
[32] H. Yanagishita, C. Maejima, D. Kitamoto, and T. Nakane, "Preparation of asymmetric polyimide membrane for water/ ethanol separation in pervaporation by the phase inversion process," Journal of Membrane Science, vol. 86, no. 3, pp. 231240, 1994.

[33] T. Sano, N. Yamashita, Y. Iwami, K. Takeda, and Y. Kawakami, "Estimation of dealumination rate of ZSM-5 zeolite by adsorption of water vapor," Zeolites, vol. 16, no. 4, pp. 258-264, 1996.

[34] T. Sano, S. Ejiri, K. Yamada, Y. Kawakami, and H. Yanagishita, "Separation of acetic acid-water mixtures by pervaporation through silicalite membrane," Journal of Membrane Science, vol. 123, no. 2, pp. 225-233, 1997.

[35] B. Smitha, D. Suhanya, S. Sridhar, and M. Ramakrishna, "Separation of organic-organic mixtures by pervaporationa review," Journal of Membrane Science, vol. 241, no. 1, pp. 1-21, 2004.

[36] C.-L. Chang and M.-S. Chang, "Preparation of composite membranes of functionalised silicone polymers and PVDF for pervaporation of ethanol-water mixture," Desalination, vol. 148, no. 1-3, pp. 39-42, 2002.

[37] J. R. González-Velasco, J. A. González-Marcos, and C. LópezDehesa, "Pervaporation of ethanol-water mixtures through poly(1-trimethylsilyl-1-propyne) (PTMSP) membranes," Desalination, vol. 149, no. 1-3, pp. 61-65, 2002.

[38] M. Krea, D. Roizard, N. Moulai-Mustefa, and D. Sacco, "Synthesis of polysiloxane-imide membranes-application to the extraction of organics from water mixtures," Desalination, vol. 163, no. 1-3, pp. 203-206, 2004.

[39] M. K. Djebbar, Q. T. Nguyen, R. Clément, and Y. Germain, "Pervaporation of aqueous ester solutions through hydrophobic poly (ether-block-amide) copolymer membranes," Journal of Membrane Science, vol. 146, no. 1, pp. 125-133, 1998.

[40] M. Matsumura and H. Kataoka, "Separation of dilute aqueous butanol and acetone solutions by pervaporation through liquid membranes," Biotechnology and Bioengineering, vol. 30, no. 7, pp. 887-895, 1987.

[41] A. Thongsukmak and K. K. Sirkar, "Pervaporation membranes highly selective for solvents present in fermentation broths," Journal of Membrane Science, vol. 302, no. 1-2, pp. 45-58, 2007.

[42] A. Hasanoğlu, Y. Salt, S. Keleşer, and S. Dinçer, “The esterification of acetic acid with ethanol in a pervaporation membrane reactor," Desalination, vol. 245, no. 1-3, pp. 662-669, 2009.

[43] M. T. Sanz and J. Gmehling, "Esterification of acetic acid with isopropanol coupled with pervaporation part I: kinetics and pervaporation studies,' Chemical Engineering Journal, vol. 123, no. 1-2, pp. 1-8, 2006.

[44] L. Domingues, F. Recasens, and M. A. Larrayoz, "Studies of a pervaporation reactor: kinetics and equilibrium shift in benzyl alcohol acetylation," Chemical Engineering Science, vol. 54, no. 10, pp. 1461-1465, 1999.

[45] Z. Koszorz, N. Nemestothy, Z. Ziobrowski, K. Belafi-Bako, and R. Krupiczka, "Influence of pervaporation process parameters on enzymatic catalyst deactivation," Desalination, vol. 162, no. 1-3, pp. 307-313, 2004.

[46] M. Zhang, L. Chen, Z. Jiang, and J. Ma, "Effects of dehydration rate on the yield of ethyl lactate in a pervaporation-assisted esterification process," Industrial \& Engineering Chemistry Research, vol. 54, no. 26, pp. 6669-6676, 2015.

[47] S. Korkmaz, Y. Salt, and S. Dincer, "Esterification of acetic acid and isobutanol in a pervaporation membrane reactor using different membranes," Industrial and Engineering Chemistry Research, vol. 50, no. 20, pp. 11657-11666, 2011.
[48] W. Zhang, W. Qing, N. Chen, Z. Ren, J. Chen, and W. Sun, "Enhancement of esterification conversion using novel composite catalytically active pervaporation membranes," Journal of Membrane Science, vol. 451, pp. 285-292, 2014.

[49] C.-J. Shieh, H.-F. Liao, and C.-C. Lee, "Optimization of lipasecatalyzed biodiesel by response surface methodology," Bioresource Technology, vol. 88, no. 2, pp. 103-106, 2003.

[50] Z. Ziobrowski, K. Kiss, A. Rotkegel, N. Nemestóthy, R. Krupiczka, and L. Gubicza, "Pervaporation aided enzymatic production of glycerol monostearate in organic solvents," Desalination, vol. 241, no. 1-3, pp. 212-217, 2009.

[51] S. H. Krishna, B. Manohar, S. Divakar, S. G. Prapulla, and N. G. Karanth, "Optimization of isoamyl acetate production by using immobilized lipase from Mucor miehei by response surface methodology," Enzyme and Microbial Technology, vol. 26, no. 2-4, pp. 131-136, 2000.

[52] A. Baudot and M. Marin, "Pervaporation of aroma compounds: comparison of membrane performances with vapour-liquid equilibria and engineering aspects of process improvement," Food and Bioproducts Processing, vol. 75, no. 2, pp. 117-142, 1997.

[53] D. Beaumelle, M. Marin, and H. Gibert, "Pervaporation with organophilic membranes: state of the art," Transactions of the Institution of Chemical Engineers C, vol. 71, no. 2, pp. 77-89, 1993.

[54] T. A. C. Oliveira, J. T. Scarpello, and A. G. Livingston, "Pervaporation-biological oxidation hybrid process for removal of volatile organic compounds from wastewaters," Journal of Membrane Science, vol. 195, no. 1, pp. 75-88, 2002.

[55] J. G. Wijmans, A. L. Athayde, R. Daniels, J. H. Ly, H. D. Kamaruddin, and I. Pinnau, "The role of boundary layers in the removal of volatile organic compounds from water by pervaporation," Journal of Membrane Science, vol. 109, no. 1, pp. 135-146, 1996.

[56] S. Ganapathi-Desai and S. K. Sikdar, "A polymer-ceramic composite membrane for recovering volatile organic compounds from wastewaters by pervaporation," Clean Products and Processes, vol. 2, no. 3, pp. 140-148, 2000.

[57] P. Cote and C. Lipski, "Mass transfer in pervaporation for water and wastewater treatment," in Proceedings of the 3rd International Conference on Pervaporation Processes and Chemical Industry, R. A. Bakish, Ed., pp. 449-462, 1988.

[58] Z. Qi and E. L. Cussler, "Membrane separation of potassium nitrate from mixed brines," Journal of Membrane Science, vol. 19, no. 3, pp. 259-272, 1984.

[59] J. G. Wijmans and R. W. Baker, "The solution-diffusion model: a review," Journal of Membrane Science, vol. 107, no. 1-2, pp. 1-27, 1995.

[60] X. Feng and R. Y. M. Huang, "Estimation of activation energy for permeation in pervaporation processes," Journal of Membrane Science, vol. 118, no. 1, pp. 127-131, 1996.

[61] A. Hillaire and E. Favre, "Isothermal and non-isothermal permeation of an organic vapor through a dense polymer membrane," Industrial and Engineering Chemistry Research, vol. 38, no. 1, pp. 211-217, 1999.

[62] P. Sampranpiboon, R. Jiraratananon, D. Uttapap, X. Feng, and R. Y. M. Huang, "Pervaporation separation of ethyl butyrate and isopropanol with polyether block amide (PEBA) membranes," Journal of Membrane Science, vol. 173, no. 1, pp. 53-59, 2000.

[63] C. K. Yeom and K.-H. Lee, "A study on desorption resistance in pervaporation of single component through dense membranes," Journal of Applied Polymer Science, vol. 63, no. 2, pp. 221-232, 1997. 
[64] A. Hasanoglu, Y. Salt, S. Keleşer, S. Özkan, and S. Dinçer, "Pervaporation separation of organics from multicomponent aqueous mixtures," Chemical Engineering and Processing: Process Intensification, vol. 46, no. 4, pp. 300-306, 2007.

[65] M. N. Hyder, R. Y. M. Huang, and P. Chen, "Effect of selective layer thickness on pervaporation of composite poly(vinyl alcohol)-poly(sulfone) membranes," Journal of Membrane Science, vol. 318, no. 1-2, pp. 387-396, 2008.

[66] A. Raisi and A. Aroujalian, "Aroma compound recovery by hydrophobic pervaporation: the effect of membrane thickness and coupling phenomena," Separation and Purification Technology, vol. 82, no. 1, pp. 53-62, 2011.

[67] J.-H. Chang, J.-K. Yoo, S.-H. Ahn, K.-H. Lee, and S.-M. Ko, "Simulation of pervaporation process for ethanol dehydration by using pilot test results," Korean Journal of Chemical Engineering, vol. 15, no. 1, pp. 28-36, 1998.

[68] M. H. V. Mulder and C. A. Smolders, "On the mechanism of separation of ethanol/water mixtures by pervaporation I. Calculations of concentration profiles," Journal of Membrane Science, vol. 17, no. 3, pp. 289-307, 1984.

[69] D. E. Daubert and R. P. Danner, Physical and Thermodynamic Properties of Pure Chemicals: Data Compilation, Design Institute for Physical Property Data, AIChE Hemisphere Publishing Corporation, 1991.

[70] J. Gmehling and U. Onken, Vapor-Liquid Equilibrium Data Collection, Aqueous-Organic Systems, vol. 1 of Dechema Chemistry Data Series, part 1, DECHEMA, Frankfurt, Germany, 1977.

[71] M. C. Burshe, S. B. Sawant, and V. G. Pangarkar, "Dehydration of glycerine-water mixtures by pervaporation," Journal of the American Oil Chemists' Society, vol. 76, no. 2, pp. 209-214, 1999.

[72] W. F. Guo, T.-S. Chung, and T. Matsuura, "Pervaporation study on the dehydration of aqueous butanol solutions: a comparison of flux vs. permeance, separation factor vs. selectivity," Journal of Membrane Science, vol. 245, no. 1-2, pp. 199-210, 2004.

[73] J. Ma, M. Zhang, L. Lu, X. Yin, J. Chen, and Z. Jiang, "Intensifying esterification reaction between lactic acid and ethanol by pervaporation dehydration using chitosan-TEOS hybrid membranes," Chemical Engineering Journal, vol. 155, no. 3, pp. 800-809, 2009.

[74] A. Svang-Ariyaskul, R. Y. M. Huang, P. L. Douglas et al., "Blended chitosan and polyvinyl alcohol membranes for the pervaporation dehydration of isopropanol," Journal of Membrane Science, vol. 280, no. 1-2, pp. 815-823, 2006.

[75] A. Thongsukmak and K. K. Sirkar, "Extractive pervaporation to separate ethanol from its dilute aqueous solutions characteristic of ethanol-producing fermentation processes," Journal of Membrane Science, vol. 329, no. 1-2, pp. 119-129, 2009.

[76] K.-H. Song, K.-R. Lee, and J.-M. Rim, "Pervaporation of esters with hydrophobic membrane," Korean Journal of Chemical Engineering, vol. 21, no. 3, pp. 693-698, 2004.

[77] B. K. Dutta and S. K. Sikdar, "Separation of volatile organic compounds from aqueous solutions by pervaporation using SB-S block copolymer membranes," Environmental Science and Technology, vol. 33, no. 10, pp. 1709-1716, 1999.

[78] Z. Guo and C. Hu, "Pervaporation of organic liquid/water mixtures through a novel silicone copolymer membrane," Chinese Science Bulletin, vol. 43, no. 6, pp. 487-490, 1998.

[79] A. Wolińska-Grabczyk, J. Muszyński, and A. Jankowski, "Applications of polyurethane-based membranes in pervaporation separations," Chemical Papers, vol. 54, no. 6, pp. 389-392, 2000.
[80] P. Maeki-Arvelaa, T. Salmia, M. Sundellb, K. Ekmanb, R. Peltonenb, and J. Lehtonen, "Comparison of polyvinylbenzene and polyolen supported sulphonic acid catalysts in the esterification of acetic acid," Applied Catalysis A: General, vol. 184, pp. 25-32, 1999.

[81] A. Izci and F. Bodur, "Liquid-phase esterification of acetic acid with isobutanol catalyzed by ion-exchange resins," Reactive and Functional Polymers, vol. 67, no. 12, pp. 1458-1464, 2007.

[82] S. R. Kirumakki, N. Nagaraju, and S. Narayanan, "A comparative esterification of benzyl alcohol with acetic acid over zeolites $\mathrm{H} \beta$, HY and HZSM5," Applied Catalysis A: General, vol. 273, no. 1-2, pp. 1-9, 2004.

[83] F. Omota, A. C. Dimian, and A. Bliek, "Fatty acid esterification by reactive distillation: part 2-kinetics-based design for sulphated zirconia catalysts," Chemical Engineering Science, vol. 58, no. 14, pp. 3175-3185, 2003.

[84] T. A. Peters, N. E. Benes, A. Holmen, and J. T. F. Keurentjes, "Comparison of commercial solid acid catalysts for the esterification of acetic acid with butanol," Applied Catalysis A: General, vol. 297, no. 2, pp. 182-188, 2006.

[85] Y.-H. Liu, Q.-S. Liu, and Z.-H. Zhang, "Amberlyst-15 as a new and reusable catalyst for regioselective ring-opening reactions of epoxides to $\beta$-alkoxy alcohols," Journal of Molecular Catalysis A: Chemical, vol. 296, no. 1-2, pp. 42-46, 2008.

[86] G. D. Yadav and M. B. Thathagar, "Esterification of maleic acid with ethanol over cation-exchange resin catalysts," Reactive and Functional Polymers, vol. 52, no. 2, pp. 99-100, 2002.

[87] Q. L. Liu and H. F. Chen, "Modeling of esterification of acetic acid with n-butanol in the presence of $\mathrm{Zr}\left(\mathrm{SO}_{4}\right) 2 \bullet_{4} \mathrm{H}_{2} \mathrm{O}$ coupled pervaporation," Journal of Membrane Science, vol. 196, no. 2, pp. 171-178, 2002.

[88] M. O. David, T. Q. Nguyen, and J. Neel, "Pervaporation esterification coupling: part I. Basic kinetic model," Transactions of the Institution of Chemical Engineers, vol. 69, p. 341, 1991.

[89] Q. Liu, Z. Zhang, and H. F. Chen, "Study on the coupling of esterification with pervaporation," Journal of Membrane Science, vol. 182, no. 1-2, pp. 173-181, 2001.

[90] L. Xuehui and W. Lefu, "Kinetic model for an esterification process coupled by pervaporation," Journal of Membrane Science, vol. 186, no. 1, pp. 19-24, 2001.

[91] A. Grob and A. Heintz, "Sorption isotherms of aromatic compounds in organophilic polymer membranes used in pervaporation," Journal of Solution Chemistry, vol. 28, no. 10, pp. 1159-1174, 1999.

[92] J. Brandrup and E. H. Immergut, Polymer Handbook, John Wiley \& Sons, New York, NY, USA, 1975.

[93] M. H. V. Mulder, Thermodynamic Principles of Pervaporation, Pervaporation Membrane Separation Processes, Elsevier, Amsterdam, The Netherlands, 1991.

[94] L. Bagnell, K. Cavell, A. M. Hodges, A. W.-H. Mau, and A. J. Seen, "The use of catalytically active pervaporation membranes in esterification reactions to simultaneously increase product yield, membrane permselectivity and flux," Journal of Membrane Science, vol. 85, no. 3, pp. 291-299, 1993.

[95] S. Korkmaz, Y. Salt, A. Hasanoglu, S. Ozkan, I. Salt, and S. Dincer, "Pervaporation membrane reactor study for the esterification of acetic acid and isobutanol using polydimethylsiloxane membrane," Applied Catalysis A: General, vol. 366, no. 1, pp.102$107,2009$.

[96] P. Delgado, M. T. Sanz, and S. Beltrán, "Pervaporation study for different binary mixtures in the esterification system of lactic 
acid with ethanol," Separation and Purification Technology, vol. 64, no. 1, pp. 78-87, 2008.

[97] K. C. S. Figueiredo, V. M. M. Salim, and C. P. Borges, "Synthesis and characterization of a catalytic membrane for pervaporation-assisted esterification reactors," Catalysis Today, vol. 133-135, no. 1-4, pp. 809-814, 2008.

[98] E. Ameri, A. Moheb, and S. Roodpeyma, "Vapor-permeationaided esterification of isopropanol/propionic acid using $\mathrm{NaA}$ and PERVAP 2201 membranes," Chemical Engineering Journal, vol. 162, no. 1, pp. 355-363, 2010.

[99] B.-G. Park and T. T. Tsotsis, "Models and experiments with pervaporation membrane reactors integrated with an adsorbent system," Chemical Engineering and Processing: Process Intensification, vol. 43, no. 9, pp. 1171-1180, 2004.

[100] Y. Zhu, R. G. Minet, and T. T. Tsotsis, "A continuous pervaporation membrane reactor for the study of esterification reactions using a composite polymeric/ceramic membrane," Chemical Engineering Science, vol. 51, no. 17, pp. 4103-4113, 1996.

[101] Y. Zou, Z. Tong, K. Liu, and X. Feng, "Modeling of esterification in a batch reactor coupled with pervaporation for production of n-butyl acetate," Chinese Journal of Catalysis, vol. 31, no. 8, pp. 999-1005, 2010.

[102] H. Zhou, Y. Li, G. Zhu, J. Liu, L. Lin, and W. Yang, "Microwave synthesis of a\&b-oriented zeolite $\mathrm{T}$ membranes and their application in pervaporation-assisted esterification," Chinese Journal of Catalysis, vol. 29, no. 7, pp. 592-594, 2008.

[103] K. Tanaka, R. Yoshikawa, C. Ying, H. Kita, and K.-I. Okamoto, "Application of zeolite membranes to esterification reactions," Catalysis Today, vol. 67, no. 1-3, pp. 121-125, 2001.

[104] K. Liu, Z. Tong, L. Liu, and X. Feng, "Separation of organic compounds from water by pervaporation in the production of n-butyl acetate via esterification by reactive distillation," Journal of Membrane Science, vol. 256, no. 1-2, pp. 193-201, 2005.

[105] A. V. Penkova, G. A. Polotskaya, and A. M. Toikka, "Separation of acetic acid-methanol-methyl acetate-water reactive mixture," Chemical Engineering Science, vol. 101, pp. 586-592, 2013.

[106] S. Khajavi, J. C. Jansen, and F. Kapteijn, "Application of a sodalite membrane reactor in esterification-coupling reaction and separation," Catalysis Today, vol. 156, no. 3-4, pp. 132-139, 2010.

[107] M. P. Bernal, J. Coronas, M. Menéndez, and J. Santamaría, "Coupling of reaction and separation at the microscopic level: esterification processes in a H-ZSM-5 membrane reactor," Chemical Engineering Science, vol. 57, no. 9, pp. 1557-1562, 2002.

[108] A. Penkova, G. Polotskaya, and A. Toikka, "Pervaporation composite membranes for ethyl acetate production," Chemical Engineering and Processing: Process Intensification, vol. 87, pp. 81-87, 2015.

[109] L. Gubicza, K. Bélafi-Bakó, E. Fehér, and T. Fráter, "Waste-free process for continuous flow enzymatic esterification using a double pervaporation system," Green Chemistry, vol. 10, no. 12, pp. 1284-1287, 2008.

[110] K. C. S. Figueiredo, V. M. M. Salim, and C. P. Borges, "Ethyl oleate production by means of pervaporation-assisted esterification using heterogeneous catalysis," Brazilian Journal of Chemical Engineering, vol. 27, no. 4, pp. 609-617, 2010.

[111] P. Luis, J. Degrève, and B. V. Bruggen, "Separation of methanol$n$-butyl acetate mixtures by pervaporation: potential of 10 commercial membranes," Journal of Membrane Science, vol. 429, pp. 1-12, 2013.
[112] U. Sander and P. Soukup, "Design and operation of a pervaporation plant for ethanol dehydration," Journal of Membrane Science, vol. 36, pp. 463-475, 1988.

[113] W. Kujawski, M. Waczyński, and M. Lasota, "Pervaporation properties of dense polyamide- 6 membranes in separation of water-ethanol mixtures," Separation Science and Technology, vol. 31, no. 7, pp. 953-963, 1996.

[114] R. W. Tock, J. Y. Cheung, and R. L. Cook, "Dioxane-water transport through nylon 6 membranes," Separation Science, vol. 9, no. 5, pp. 361-379, 1974.

[115] R. Y. M. Huang, Y. Xu, Y. Jin, and C. Lipski, "Novel blended nylon membranes for the pervaporation separation of acetic acid-water and ethanol-water liquid mixture water systems," in Proceedings of the 2nd International Conference on Pervaporation Processes in the Chemical Industry, R. Bakish, Ed., pp. 225239, Materials Corporation, San Antonio, Tex, USA, March 1987.

[116] W. Kujawski, Q. T. Nguyen, and J. Neel, "Pervaporation of wateralcohols mixtures through nafion 117 and poly(ethylene-costyrene sulfonate) interpolymer membranes," in Proc. Ill Int. Conf. on PV Proc. in the Chem. Ind, Nancy, France 1988, R. Bakish, Ed., p. 355, Bakish Materials Corporation, Englewood, NJ, USA, 1988.

[117] W. Featherstone and T. Cox, "Separation of aqueous-organic mixtures by pervaporation," British Chemical Engineering and Process Technology, vol. 16, pp. 817-819, 1971.

[118] S. Kimura and T. Nomura, "Pervaporation of organic substance water system with silicon rubber membrane," Maku, vol. 8, pp. 177-183, 1983.

[119] W. J. Groot, R. G. M. Van Der Lans, and K. C. A. M. Luyben, "Pervaporation of fermentation products," in Proc. 3rd Int. Conf. on PV Proc. in the Chem. Ind, Nancy, France 1988, R. Bakish, Ed., p. 398, Bakish Materials Corporation, Englewood, NJ, USA, 1988.

[120] W. Kujawski, "Pervaporative removal of organics from water using hydrophobic membranes. Binary mixtures," Separation Science and Technology, vol. 35, no. 1, pp. 89-108, 1999.

[121] M. Kondo, M. Komori, H. Kita, and K.-I. Okamoto, “Tubular type pervaporation module with zeolite NaA membrane," Journal of Membrane Science, vol. 133, no. 1, pp. 133-141, 1997.

[122] F. M. Velterop, Pervatech Selective Ceramic Membranes. Information Leaflet, Pervatech, Rijssen, The Netherlands, 1999.

[123] H. L. Fleming and C. S. Slater, "Pervaporation," in Membrane Handbook, W. S. W. Ho and K. K. Sirkar, Eds., chapter 10, p. 105, Van Nostrand Reinhold, New York, NY, USA, 1992.

[124] M. Zhou, M. Persin, W. Kujawski, and J. Sarrazin, "Electrochemically synthesised polypyrrole membranes for the separation of organic mixtures by pervaporation," in Proc. 7th Int. Conf. on Pervaporation (Reno, Nevada USA, 1995), R. Bakish, Ed., p. 193, Bakish Materials Corporation, Englewood, NJ, USA, 1995.

[125] Z. Yun, T. Zhangfa, L. Kun, and F. Xianshe, "Modeling of esterification in a batch reactor coupled with pervaporation for production of n-butyl acetate," Chinese Journal of Catalysis, vol. 31, no. 8, pp. 999-1005, 2010.

[126] A. Ishikawa, T. H. Chiang, and F. Toda, "Separation of wateralcohol mixtures by permeation through a zeolite membrane on porous glass," Journal of the Chemical Society, Chemical Communications, vol. 12, pp. 764-765, 1989.

[127] K. Okamoto, N. Tanihara, H. Watanabe et al., "Vapor permeation and pervaporation separation of water-ethanol mixtures through polyimide membranes," Journal of Membrane Science, vol. 68 , no. 1-2, pp. 53-63, 1992. 
[128] X. Feng and R. Y. M. Huang, "Studies of a membrane reactor: esterification facilitated by pervaporation," Chemical Engineering Science, vol. 51, no. 20, pp. 4673-4679, 1996.

[129] E. Sert and F. S. Atalay, " $n$-Butyl acrylate production by esterification of acrylic acid with $n$-butanol combined with pervaporation," Chemical Engineering and Processing: Process Intensification, vol. 81, pp. 41-47, 2014.

[130] K. C. S. Figueiredo, V. M. M. Salim, and C. P. Borges, "Ethyl oleate production by means of pervaporation-assisted esterification using heterogeneous catalysis," Brazilian Journal of Chemical Engineering, vol. 27, no. 4, pp. 609-617, 2010.

[131] K. Wasewar, S. Patidar, and V. K. Agarwal, "Esterification of lactic acid with ethanol in a pervaporation reactor: modeling and performance study," Desalination, vol. 243, no. 1-3, pp. 305313, 2009.

[132] A. P. Rathod, K. L. Wasewar, and S. S. Sonawane, "Intensification of esterification reaction of lactic acid with iso-propanol using pervaporation reactor," Procedia Engineering, vol. 51, pp. 456460, 2013.

[133] A. P. Rathod, K. L. Wasewar, and S. S. Sonawane, "Enhancement of esterification reaction by pervaporation reactor: an intensifying approach," Procedia Engineering, vol. 51, pp. 330-334, 2013.

[134] G. S. Gokavi, M. G. Mali, U. V. Desai, and T. M. Aminabhavi, "Highly water selective mixed matrix blend membranes of poly(vinyl alcohol)-poly(vinyl pyrolidone) incarporating phosphomolybdic acid for application in pervaporation assisted esterification of acetic acid with ethanol," Procedia Engineering, vol. 44, pp. 845-846, 2012. 

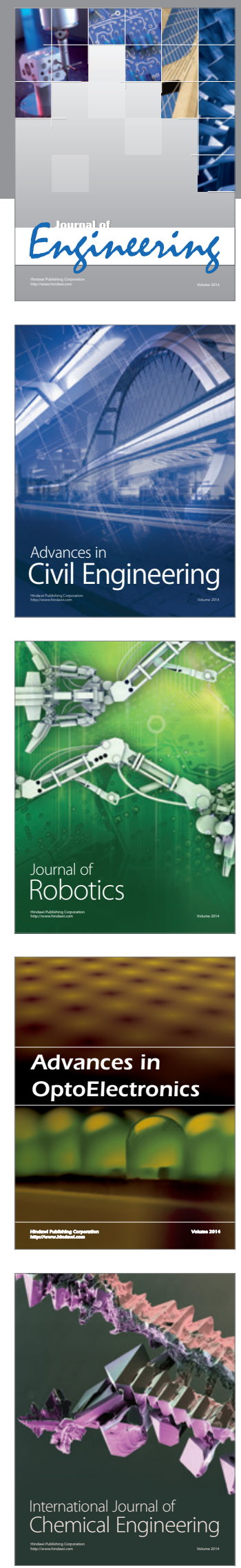

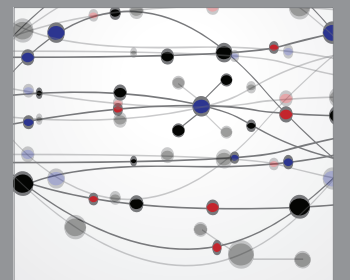

The Scientific World Journal
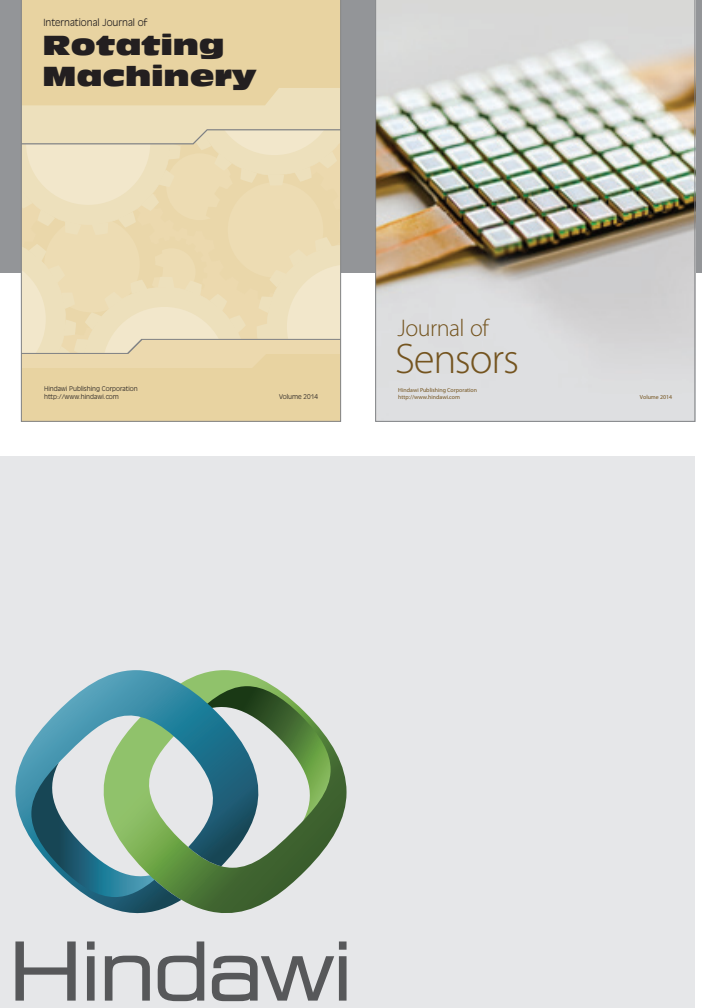

Submit your manuscripts at http://www.hindawi.com
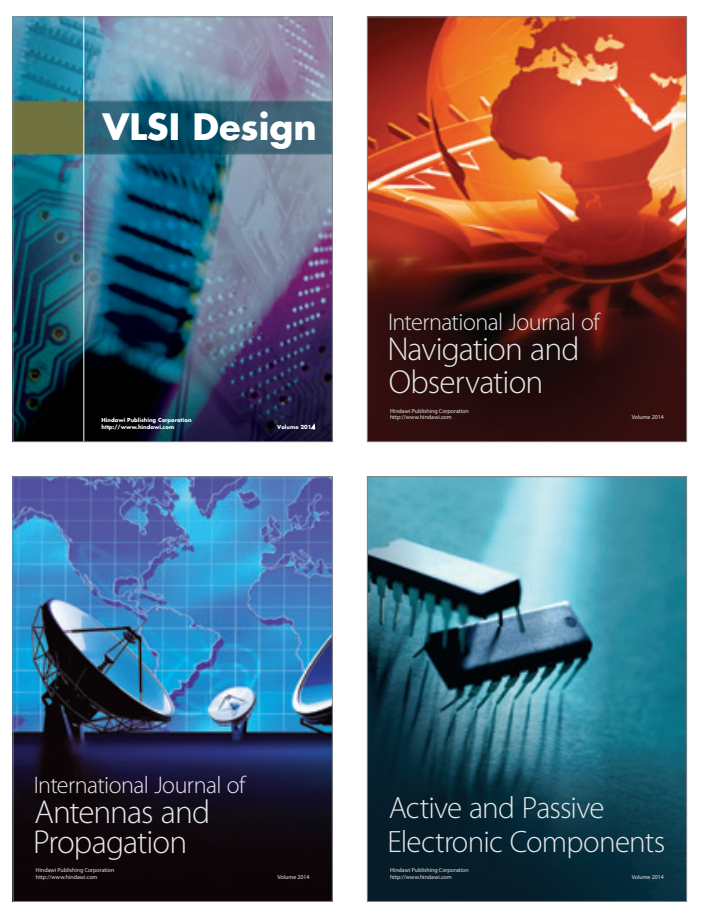
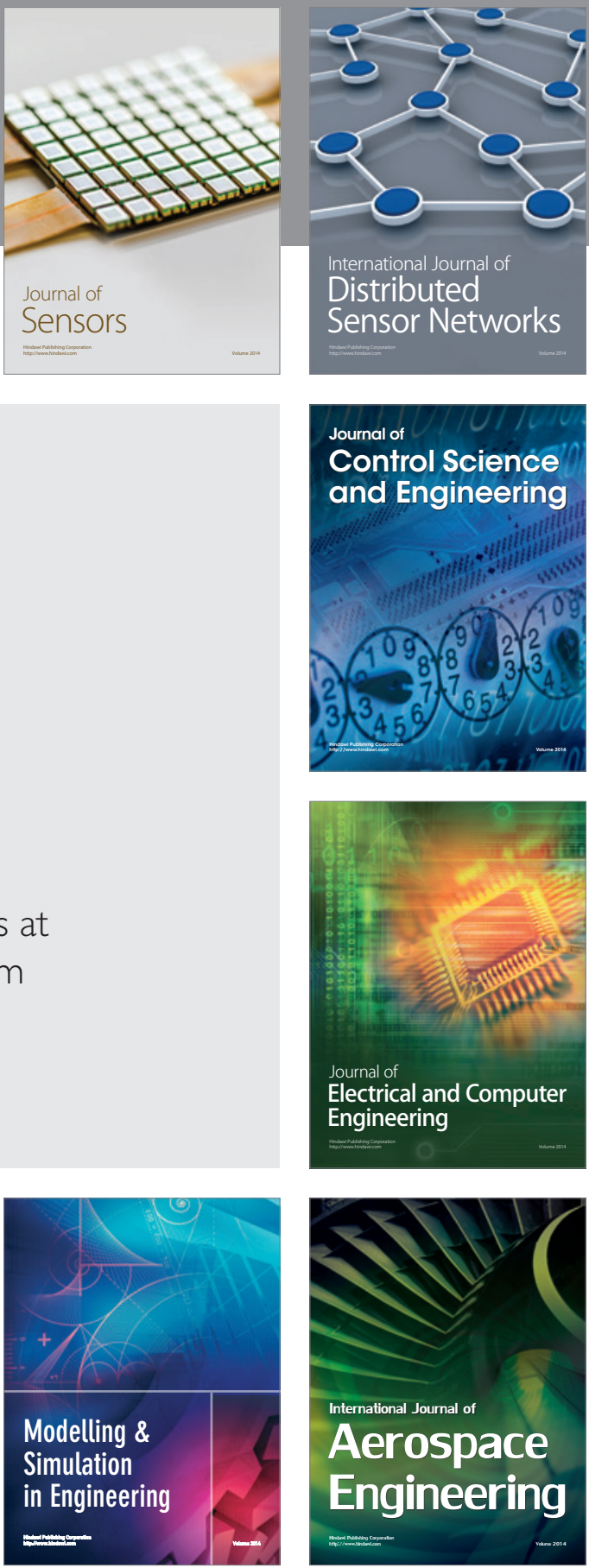

Journal of

Control Science

and Engineering
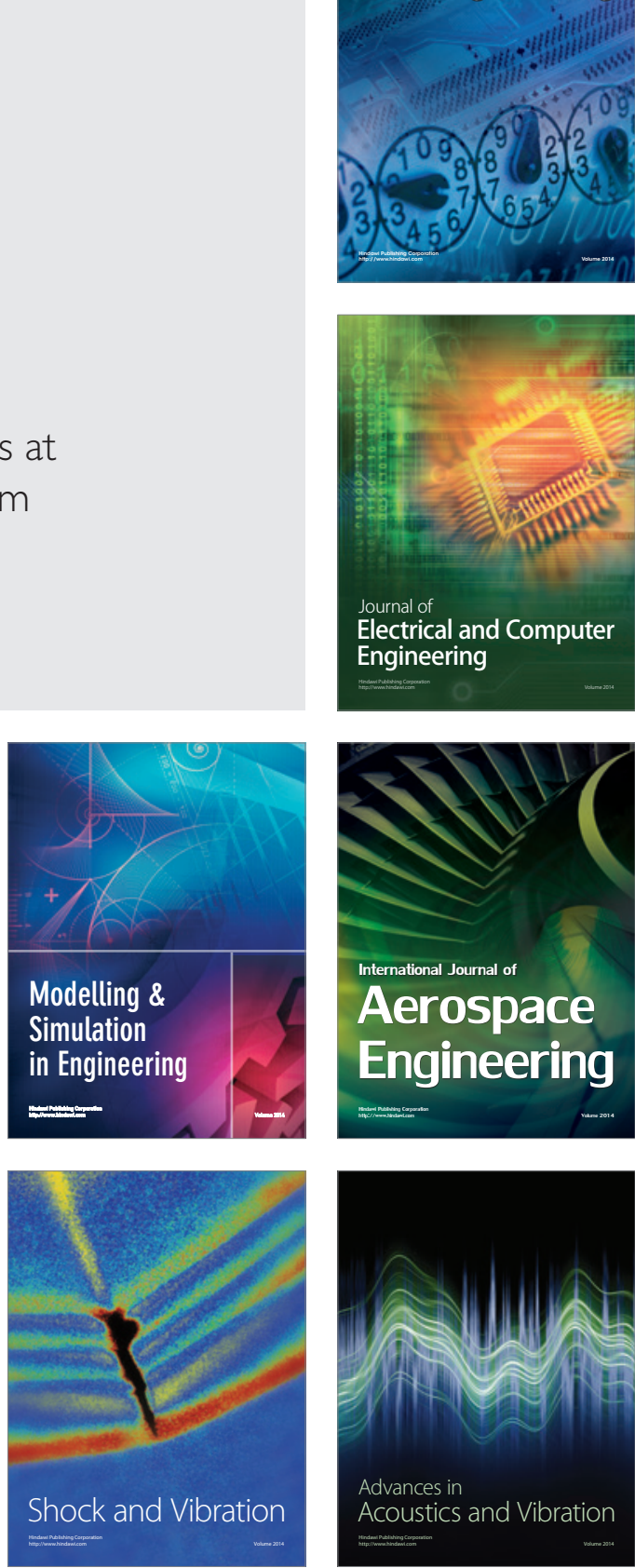